\title{
Mercury vapor air-surface exchange measured by collocated micrometeorological and enclosure methods - Part II: Bias and uncertainty analysis
}

\author{
W. Zhu ${ }^{1,2}$, J. Sommar ${ }^{1}$, C.-J. Lin ${ }^{1,3,4}$, and X. Feng ${ }^{1}$ \\ ${ }^{1}$ State Key Laboratory of Environmental Geochemistry, Institute of Geochemistry, Chinese Academy of Sciences, \\ Guiyang 550002, China \\ ${ }^{2}$ University of Chinese Academy of Sciences, Beijing 100049, China \\ ${ }^{3}$ Department of Civil Engineering, Lamar University, Beaumont, TX 77710, USA \\ ${ }^{4}$ College of Environment and Energy, South China University of Technology, Guangzhou 510006, China
}

Correspondence to: X. Feng (fengxinbin@vip.skleg.cn) and J. Sommar (jonas@vip.skleg.cn)

Received: 18 November 2014 - Published in Atmos. Chem. Phys. Discuss.: 18 February 2015

Revised: 23 April 2015 - Accepted: 24 April 2015 - Published: 18 May 2015

\begin{abstract}
Dynamic flux chambers (DFCs) and micrometeorological (MM) methods are extensively deployed for gauging air-surface $\mathrm{Hg}^{0}$ gas exchange. However, a systematic evaluation of the precision of the contemporary $\mathrm{Hg}^{0}$ flux quantification methods is not available. In this study, the uncertainty in $\mathrm{Hg}^{0}$ flux measured by the relaxed eddy accumulation (REA) method, the aerodynamic gradient method (AGM), the modified Bowen ratio (MBR) method, as well as DFC of traditional (TDFC) and novel (NDFC) designs, are assessed using a robust data set from two field intercomparison campaigns.

The absolute precision in $\mathrm{Hg}^{0}$ concentration difference $(\Delta C)$ measurements is estimated at $0.064 \mathrm{ng} \mathrm{m}^{-3}$ for the gradient-based MBR and AGM systems. For the REA system, the parameter is $\mathrm{Hg}^{0}$ concentration $(C)$ dependent at $0.069+0.022 C$. During the campaigns, 57 and $62 \%$ of the individual vertical gradient measurements are found to be significantly different from 0 , while for the REA technique, the percentage of significant observations is lower. For the chambers, non-significant fluxes are confined to a few nighttime periods with varying ambient $\mathrm{Hg}^{0}$ concentrations. Relative bias for DFC-derived fluxes is estimated to be $\sim \pm 10$, and $\sim 85 \%$ of the flux bias is within $\pm 2 \mathrm{ng} \mathrm{m}^{-2} \mathrm{~h}^{-1}$ in absolute terms. The DFC flux bias follows a diurnal cycle, which is largely affected by the forced temperature and irradiation bias in the chambers. Due to contrasting prevailing micrometeorological conditions, the relative uncertainty (median) in
\end{abstract}

turbulent exchange parameters differs by nearly a factor of 2 between the campaigns, while that in $\Delta C$ measurement is fairly consistent. The estimated flux uncertainties for the triad of MM techniques are 16-27, 12-23 and 19-31\% (interquartile range) for the AGM, MBR and REA methods, respectively. This study indicates that flux-gradient-based techniques (MBR and AGM) are preferable to REA in quantifying $\mathrm{Hg}^{0}$ flux over ecosystems with low vegetation height. A limitation of all $\mathrm{Hg}^{0}$ flux measurement systems investigated is their inability to obtain synchronous samples for the calculation of $\Delta C$. This reduces the precision of flux quantification, particularly in the MM systems under non-stationarity of ambient $\mathrm{Hg}^{0}$ concentration. For future applications, it is recommended to accomplish $\Delta C$ derivation from simultaneous collected samples.

\section{Introduction}

The volatility of atomic mercury $\left(\mathrm{Hg}^{0}\right)$ adds to the complexity of the element biogeochemical cycle. Mercury differs from other heavy metals in that it continuously goes through deposition and re-emission cycles after it is released into the atmosphere, thus exhibiting extensive dynamic cycling among environmental compartments (Schroeder and Munthe, 1998). While assessments of $\mathrm{Hg}$ burden in various environmental compartments are rather concordant, the 
fluxes between them are less well constrained (Selin, 2009). $\mathrm{Hg}^{0}$ flux measurements in terrestrial ecosystems are predominantly conducted by dynamic flux chambers (DFCs) and, to a lesser extent, by micrometeorological (MM) methods, which differ in measurement principles and spatial scale of flux footprint (Gustin, 2011). An advantage of the MM techniques compared to chambers is the measurement under undisturbed conditions. However, this also implies practical disadvantages in that $\mathrm{Hg}^{0}$ has to be detected at ambient level, and in that small temporal concentration fluctuations or vertical gradients have to be resolved. A DFC system derives flux from a steady-state mass balance and, after deployment, there is build-up of an excess (or deficit) of $\mathrm{Hg}^{0}$ concentration inside the enclosure compared to ambient air. $\mathrm{Hg}^{0}$ concentration differences between the inlet and outlet of a DFC must exceed the system blank to obtain statistical significant fluxes (Eckley et al., 2010). DFCs of different sizes, shapes and operation flow rates yield different $\mathrm{Hg}^{0}$ fluxes under identical environmental conditions (Wallschläger et al., 1999; Zhang et al., 2002; Eckley et al., 2010). More recently, we designed and deployed a DFC of novel design (NDFC) based on surface wind shear conditions (friction velocity) rather than on an artificial fixed flow to account for natural shear conditions (Lin et al., 2012). Nonetheless, implementing a new DFC design prompts a thorough comparison of in-field collected flux data by the different DFC techniques. It is also important to characterize the effects of enclosure on the microclimate over diurnal cycles, particularly temperature and radiation balance, that may lead to erroneous flux quantification as observed for other trace gases (Denmead, 2008).

The preferred MM technique, eddy covariance (EC), a direct flux measurement method without any applications of empirical constants, requires a fast response $(\sim 10 \mathrm{~Hz})$ gas analyzer, and has not been realized for $\mathrm{Hg}^{0}$. Although newly developed fast instruments for $\mathrm{Hg}^{0}$ have been tested and validated, their precision needs improvements to perform regular $\mathrm{Hg}^{0}$-EC flux measurements (Pierce et al., 2013; Bauer et al., 2014). MM techniques used to quantify $\mathrm{Hg}^{0}$ (turbulent) flux include relaxed eddy accumulation (REA), a modified Bowen ratio (MBR), and the aerodynamic gradient method (AGM). These techniques derive flux from a measured concentration difference $(\Delta C)$ and $\mathrm{MM}$ quantities, where the latter are based on EC measurements. The quality of and uncertainty in EC data can be assessed by applying well-established tests and algorithms implemented in open-source software packages designed for processing EC raw data (Aubinet et al., 2012; Fratini and Mauder, 2014). EC data of high quality are typically associated with relative sampling uncertainties of less than $20 \%$ (Mauder et al., 2013). Giving the challenge in accurate measurement of $\Delta C$, the precision with which the operational MM system can resolve small $\Delta C$ (typically at a few \%) (Sommar et al., 2013a) may render a large proportion of flux data insignificant at pristine sites (Fritsche et al., 2008). Especially the performance of REA systems is sensitive to bias between the gas sampling pathways, indicating the need to exercise a stringent QA / QC protocol on the gas sampling and chemical analytical system over time (Moravek et al., 2014; Nemitz et al., 2001).

Most studies that investigated $\mathrm{Hg}^{0}$ flux did not consider uncertainty in and potential bias of the applied techniques, nor did they present uncertainty in the calculated fluxes (Mason, 2009). A limited number of studies show and discuss sampling errors. Smith and Reinfelder (2009) tabulated uncertainties $(9-95 \%)$ for individual $\mathrm{AGM} \mathrm{Hg}^{0}$ fluxes over wetlands without information on compartmentalized uncertainties. Marsik et al. (2005) reported $\sim \pm 35 \%$ uncertainty in midday $\mathrm{Hg}^{0}$ turbulent fluxes observed over vegetated wetland. Meyers et al. (1996) reported \pm 30 and $\pm 35 \%$ mean uncertainties in eddy diffusivity for $\mathrm{H}_{2} \mathrm{O}$ and $\mathrm{CO}_{2}$ proxy scalars when applying the MBR method to measure $\mathrm{Hg}^{0}$ flux over forest floor soil and lake. Fritsche et al. (2008) estimated the relative uncertainty for the AGM and MBR method to be $\sim 43$ and $\sim 14 \%$ over grassland. Moreover, there is a lack of detailed comparisons that assess both differences and uncertainties among contemporary MM and DFCs techniques to quantify $\mathrm{Hg}^{0}$ flux under varying conditions. We have recently improved a number of $\mathrm{Hg}^{0}$ flux measurement platforms (Lin et al., 2012; Sommar et al., 2013b; Zhu et al., 2013a) and performed an integrated field comparison of collocated MM (REA, MBR and AGM) and DFC (traditional and novel-type) systems. The results are presented in two companion papers. In Part I, the five systems and their measured fluxes were cross-examined with respect to magnitude, temporal trend and correlation with environmental variables (Zhu et al., 2015). In this Part II, the objective is to investigate the quality of the flux data by quantifying measurement error under varying meteorological conditions. A bottomup assessment where the uncertainty arising from individual terms in the flux calculation formula is conservatively evaluated and combined by standard Gaussian error propagation (Wolff et al., 2010). We evaluate random and systematic errors in $\Delta C$ by performing in-field extended side-by-side measurements for the REA- and gradient-based methods. In addition, we provide theoretical precision requirements for the involved systems to resolve fluxes with regard to varying micrometeorological conditions experienced during the field assessment. Using ambient and DFC internal measured parameters to address for chamber effects as input, empirical flux models are developed to estimate bias in the DFC fluxes. Limitations and sources of uncertainties are discussed in connection with previous relevant studies, and future directions for improvements are given as well as aim to strengthen the technical merits of each technique.

\section{Site description, measurements and data processing}

The instrumentation setup, quality control measures and a full site description have been described in the Part I pa- 
per (Zhu et al., 2015). Briefly, two field campaigns were performed in late autumn 2012 (IC no. 1, bare ploughed soil fetch, 4-24 November, DOY 309-329) and spring 2013 (IC no. 2, low-standing wheat canopy, 16-25 April, DOY 106-115) over agricultural fields inside Yucheng Comprehensive Experimental Station (YCES) located on the North China Plain $\left(36^{\circ} 57^{\prime} \mathrm{N}, 116^{\circ} 36^{\prime} \mathrm{E}\right)$. The terrain was relatively flat with homogeneous distribution of soil $\mathrm{Hg}$ $\left(45.0 \pm 3.9 \mu \mathrm{g} \mathrm{kg}^{-1}, n=27\right)$. IC no. 1 was conducted over the ploughed bare soil surface using AGM, MBR, TDFC, and NDFC. IC no. 2 was performed over wheat (height $\sim 0.36 \mathrm{~m}$, leaf area index of 3.4) using REA, AGM, and MBR. All MM measurements were conducted using instrumentation mounted on a $\sim 6.5 \mathrm{~m}$ high flux tower. The REA sampling intake ( $z_{\text {REA }}, 2.96 \mathrm{~m}$ a.g.l.) was collocated with upper intake of the gradient system $\left(z_{2}\right)$, while the lower intake $\left(z_{1}\right)$ was at $0.76 \mathrm{~m}$ a.g.l. Temperature and humidity sensors (HMP 155A, Vaisala Oy, Finland) housed in radiation shields were positioned at $z_{2}$ and $z_{1}$ level. The three MM systems were independently operated using separate sets of two three-way automated magnetic switching units $\left(\right.$ Tekran $\left.{ }^{\circledR} 1110\right)$ coupled with the respective automated Tekran ${ }^{\circledR}$ model 2537B Hg vapor analyzer (Tekran Instruments Corp.). Accumulated updraft and downdraft and two-height level air were sampled in sequences of $10 \mathrm{~min}$ intervals (two $5 \mathrm{~min}$ samples). The TDFC and NDFC were operated in tandem at a flow rate of $15 \mathrm{~L} \mathrm{~min}^{-1}$ with the inlet and outlet coupled to one 2537B instrument via a four-port switching manifold $\left(\right.$ Tekran $^{\circledR}$ model 1115).

Approximately $15 \%$ of the measurement periods were dedicated to calibrations, blank testing and other QA / QC measures. Tests were applied to the fast time $(0.1 \mathrm{~s})$ series of raw data derived from the OPEC system (open path eddy covariance) instrumentation for each of the, all told, 1645 flux (20 min) measurement periods to assess the turbulence qualitatively and to address the associated size of the MMtechnique flux footprint using the Eddypro ${ }^{\mathrm{TM}} 5.0$ flux analysis software package (LI-COR Biosciences Inc.). To indicate periods of limited turbulent mixing, all the individual flux data were flagged using the basic 0-1-2 system scale scheme described in Mauder and Foken (2004), where class 2 indicates a hard flag (low data quality). The data assigned for high (Flag 0) and moderate (Flag 1) turbulence quality (with respect to sensible heat flux) corresponded to 55 and $81 \%$ of the flux observations during IC no. 1 and IC no. 2 , respectively ( $66 \%$ in total). Periods when horizontal wind approached the sampling tower within the immediate $\pm 15^{\circ}$ sector of the opposite direction from which the sonic anemometer head (and sampling inlets) was pointing were hard-flagged to account for potentially disturbances of the wind field. This yielded an additional $4 \%$ of the data classified by Flag 2. The representatives of 20 min fluxes were checked by footprint analysis (Zhu et al., 2015), but occasioned no additional flags, since the sampling tower is predominately surrounded by continuous farmlands within a $\sim 2 \mathrm{~km}$ radius. Hard-flagged data denote periods of greater uncertainty in the turbulent fluxes and the uncertainty quantification itself may become questionable (Mauder et al., 2013). The qualitative information derived from diagnostic flags serves as a guide for further quantitative assessment of uncertainties.

\section{Methodology}

Error is a single value indicating the difference between an individual measurement and the true quantity being measured. In practice, an observed measurement error is the difference between the observed value and a reference value (Ellison and Williams, 2012). For measurement $(x)$ of an arbitrary quantity $(\hat{x})$, the observation can be expressed as $x=\hat{x}+\varepsilon_{x} \pm \delta_{x}$, where $\varepsilon_{x}$ and $\delta_{x}$ represent systematic (bias) and random errors, respectively. As far as possible, errors should be traced, and minimized when possible, and nevertheless accounted for by applying corrections, while resulting stochastic uncertainties associated with the precision of a measurement should be estimated and stated (Billesbach, 2011). Measured fluxes are estimates of unknown quantities of air-surface exchange under field conditions and a reference technique for validating the estimates does not exist. Identified flux bias from side-by-side measurement was corrected for, while resulting uncertainties associated with the flux measurement were combined by standard Gaussian error propagation.

\subsection{Calibration, detection limit and uncertainty in the concentration measurements}

Multiple Tekran ${ }^{\circledR} 2537$ mercury vapor analyzers were deployed in this study. For each analyzer, a pre-filtered sample air stream is passed through a gold cartridge that traps $\mathrm{Hg}$ by amalgamation, which then is thermo-desorbed and detected by atomic fluorescence spectrophotometry. The instrument utilizes two gold cartridges in parallel, with alternating operation modes (sampling and desorbing/analyzing in a $\mathrm{Hg}$-free Ar stream) on a pre-defined time base of $5 \mathrm{~min}$ to allow for continuous operation. The instrument is equipped with an internal permeation source (secondary standard, VICI Metronics Inc., Paulsbo, USA) that can be invoked automatically to perform two-point calibrations with a span value of $\sim 150 \mathrm{pg}$ and a zero-air reference point (exclusively no detectable peak using default integration parameters). The photo-multiplier sensitivity was typically at $6-9 \times 10^{6}$ area unit per $\mathrm{ng} \mathrm{Hg}$ (response factor). The three Tekran 2537B instruments deployed were operated under the AMNet standard operation procedure (SOP) protocol (NADP, 2011). The internal calibration system (within $\pm 4 \%$ repeatability for regular $48 \mathrm{~h}$ calibrations of the individual Tekran 2537Bs) was verified prior to each of the field campaigns using syringe injection from a saturated $\mathrm{Hg}^{0}$ vapor source in a thermostatically 
controlled water bath. Repeated injections yielded recoveries within $\pm 2 \%$ (range: $98-101 \%$ ) of the expected amount $\mathrm{Hg}$ injected, also taking the temperature difference between the reservoirs into consideration (Brown and Brown, 2008). Consequently, our mass concentration measurements of $\mathrm{Hg}^{0}$ are traceable to the accuracy at which $\mathrm{Hg}^{0}$ vapor pressure can be gauged. For this purpose, we deployed the commonly used so-called Dumarey equation (Dumarey et al., 1985, 2010). The performance of the (A-B) pair of gold cartridges in each of the 2537Bs was evaluated prior to each campaign. In case a significant difference $(>5 \%)$ in the A versus B cartridge response to calibration spans or persistent significant bias ( $t$ test, $P<0.05$ ) existed between A and B when monitoring ambient air, the peculiar pair was replaced with a fresh one. Further inter-comparisons indicated that no discernible bias or trends deviating from a 1:1 relationship proceed.

The uncertainty in concentration measurement depends on the individual uncertainties in the sample volume, the peak integration and the field calibration procedure. The sample volume is derived from an internal mass flow controller (MFC, Bronkhorst High-Tech B. V., Ruurlo, Netherlands) and reported exclusively within $\pm 0.01 \mathrm{~L}$ of the pre-defined volume. To verify the performance of the MFC, the sampling air flow into the 2537Bs was also measured using an electronic bubble flow meter (Gillibrator, Sensidyne Inc., St. Petersburg, USA). The detector output signal was set in the range $0.15-0.25 \mathrm{~V}$ and showed satisfactorily low baseline standard deviations in general of $<80 \mu \mathrm{V}$. The default fluorescence peak integration scheme of 2537B is designed for moderate $\mathrm{Hg}$ loadings per sampling cycle (i.e., $10-15 \mathrm{pg}$ ). At smaller loadings, this scheme introduces a nonlinearly growing relative concentration bias (biased low) with decreasing peak area (Swartzendruber et al., 2009). For one of our applications, the coupling of the REA system with a 2537B yielded sub-optimal $\mathrm{Hg}$ mass loadings (typically $2-8$ pg per cycle due to the injection of $\mathrm{Hg}$ zero air). To mitigate for this critical effect, the REA-coupled 2537B was operated under a revised scheme of parameters, resulting in a slightly longer and fixed integration time (Swartzendruber et al., 2009). For the remaining 2537Bs (DFCs and the gradient sampling system, respectively), the integration parameters remained at default level during operation. The 2537B detection limit with this peak integration scheme is at $\sim 0.10 \mathrm{ng} \mathrm{m}^{-3}$.

\subsection{Derivation of concentration difference detection limit, bias and uncertainty}

All the examined flux techniques rely on measurement of $\mathrm{Hg}^{0}$ concentration differences as shown in Eqs. (1)-(5) for the TDFC, NDFC, REA, AGM and MBR systems, respectively. In this paper, all equation symbols with corresponding units are summarized and explained in Appendix A.

$$
F^{\mathrm{TDFC}}=\frac{Q \cdot\left(C_{\mathrm{out}}-C_{\mathrm{in}}\right)}{A}=\frac{Q}{A} \cdot \Delta C_{\mathrm{enclosure}}^{\mathrm{TDFC}}
$$

$$
\begin{aligned}
& F^{\mathrm{NDFC}}=\frac{Q \cdot\left(C_{\mathrm{out}}-C_{\mathrm{in}}\right)}{A} \frac{k_{\mathrm{mass}(\mathrm{a})}}{k_{\mathrm{mass}(\mathrm{m})}}= \\
& \frac{Q}{A} \cdot \Delta C_{\text {enclosure }}^{\mathrm{NDFC}} \cdot \frac{\left(4.86+\frac{3.625 \times 10^{-6} \cdot u_{*} /\left(z_{0} \cdot D_{\mathrm{Hg}, \mathrm{air}}\right)}{1+3.911 \times 10^{-5} \cdot\left[u_{*} /\left(z_{0} \cdot D_{\mathrm{Hg}, \mathrm{air}}\right)\right]^{2 / 3}}\right)}{\left(4.86+\frac{3.633 \times 10^{-2} \cdot Q / D_{\mathrm{Hg}, \mathrm{air}}}{1+1.818 \times 10^{-2} \cdot\left(Q / D_{\mathrm{Hg}, \mathrm{air}}\right)^{2 / 3}}\right)} \\
& \left.F^{\mathrm{REA}}\right|_{z_{2}}=\beta_{s} \sigma_{w} \underbrace{\left(\overline{C^{\uparrow}}-\overline{C^{\downarrow}}\right)}_{\Delta C_{\mathrm{REA}}}= \\
& \beta_{s} \sigma_{w}\left\{\sum_{i} \frac{m_{i}^{\uparrow}}{t_{i} \cdot Q_{i}^{\uparrow} \cdot \alpha_{i}^{\uparrow}}-\sum_{j} \frac{m_{j}^{\downarrow}}{t_{j} \cdot Q_{j}^{\downarrow} \cdot \alpha_{j}^{\downarrow}}\right\} \\
& F^{\mathrm{AGM}}=-K_{H}\left(u_{*}, \varsigma\right) \frac{\partial C}{\partial z}= \\
& -\underbrace{\frac{\kappa u_{*}}{\ln \left(\frac{z_{2}-d}{z_{1}-d}\right)-\psi_{H}\left(\varsigma_{2}\right)+\psi_{H}\left(\varsigma_{1}\right)}}_{v_{\text {tr }}} \cdot \underbrace{\left(C_{z_{2}}-C_{z_{1}}\right)}_{\Delta C_{\text {grad. }}} \\
& F^{\mathrm{MBR}}=\overline{w^{\prime} T^{\prime}} \cdot \frac{C_{z_{2}}-C_{z_{1}}}{T_{z_{2}}-T_{z_{1}}}=\overline{w^{\prime} T^{\prime}} \cdot \frac{\Delta C_{\mathrm{grad}}}{\Delta T_{\mathrm{grad}}}
\end{aligned}
$$

Since a single $2537 \mathrm{~B}$ does not have the ability to analyze samples from two channels synchronously, the calculation of concentration difference is based on temporally intermittent concentration measurement. This means that uncertainties in $\Delta C$ of Eqs. (1)-(5) (i.e., $\Delta C_{\text {enclosure, }} \Delta C_{\mathrm{REA}}$ and $\Delta C_{\text {grad. }}$ ) include a contribution from sampling channels (for enclosures, the chamber blank) as well as from non-stationarity in $\mathrm{Hg}^{0}$ concentration during the collection of asynchronous samples. The combined uncertainty due to analytical precision and intermittent sampling is expressed as $\delta_{\Delta C_{\mathrm{MM}}}= \pm \sqrt{\left(\delta_{\Delta C_{\mathrm{MM}}}^{\text {channel }}\right)^{2}+\left(\delta_{\Delta C_{\mathrm{MM}}}^{\mathrm{IS}}\right)^{2}}$ and $\delta_{\Delta C_{\text {enclosure }}}=$ $\pm \sqrt{\left(\delta_{\Delta C_{\text {enclosure }}}^{\text {IS }}\right)^{2}+\delta_{\Delta C_{\text {blank }}}^{2}}$ for the MM and DFC systems, respectively. For the enclosures deployed, system blanks were determined during daytime in the field with the DFCs placed on an acid-cleaned FEP sheet. Our REA system enables a mode in which air is sampled synchronously with both conditional inlets (Sommar et al., 2013b). This referencing mode provides an automated QC measure to regularly check for gas sampling path bias and to estimate the precision of $\Delta C_{\text {REA }}$. To investigate and characterize bias and the precision of concentration difference measurements, we performed extended side-by-side measurements with the gradient system and regular periods of reference mode sampling with the REA system during the field experiments. The sign of $\Delta C$ states the direction of vertical flux derived and therefore its uncertainty determines the limit at which flux can be detected. Detection limits under field conditions were derived based on the standard deviation of the residuals from orthogonal linear regression fitting. 


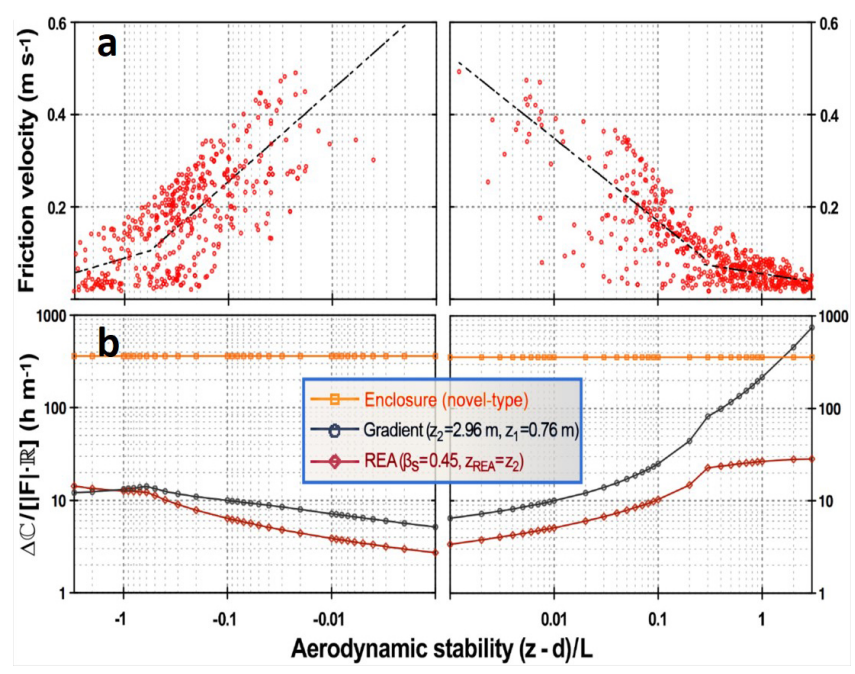

Figure 1. (a) Upper panel: Lin-log scatterplot of observed friction velocity $\left(u_{*}\right)$ versus aerodynamic stability $(\varsigma=(z-d) / L)$ during IC no. 1 . The dashed lines indicate the parameterization $u_{*}=\ell(\varsigma)$ used for calculations of analyzer resolution requirements for the MM techniques. (b) Lower panel: comparison of the required sensor resolution (expressed as $\Delta \mathbb{C} /[\mathbb{R} \cdot|F|]$ as a function of stability for REA, gradient-based and enclosure methods (double logarithmic plot).

\subsection{Constraints on $\mathrm{Hg}^{0}$ analyzer resolution for the flux measurement methods}

The MM and DFC techniques rely on entirely independent principles. Even at the high air exchange rates $(\sim 3.1$ and $\sim 2.1 \mathrm{~min}^{-1}$ for TDFC and NDFC) used in this study, there is an inevitable build-up of an excess (or deficit) of $\mathrm{Hg}^{0}$ concentration inside the enclosure compared to ambient air. The concentration difference to be resolved depends on the magnitude of the flux, but, for MM techniques, also on atmospheric stability conditions and measurement height. The method-specific analyzer concentration difference resolution $(\Delta \mathbb{C})$ required to achieve a given uncertainty $(\mathbb{R})$ in the flux measurement under the set of atmospheric conditions given during IC no. 1 was estimated using the approach of Businger and Delany (1990) modified by Rowe et al. (2011). The analysis is presented as a function of the parameters $u_{*}$ and $\varsigma$ :

$\Delta \mathbb{C}=\mathbb{R} \cdot|F| \cdot \mathrm{AP}_{x}(\varsigma) / u_{*}$,

where $|F|$ and $\operatorname{AP}_{x}(\varsigma)$ are explained in Appendix A. For REA with a deadband of $\pm 0.3 \cdot \sigma_{w}, \beta_{s}=0.45$ was used in this example. Observations of high friction velocities normally resulted in nearly neutral stratification, whereas low winds led to either significant stable or unstable conditions (Fig. 1a). Following Ammann (1998), for typical daytime (unstable) and night-time (stable) conditions, respectively, a piecewise logarithmic parameterization of $u_{*}$ as a function of $\varsigma(\ell(\varsigma))$ was applied (dashed lines in Fig. 1a) to reduce Eq. (6) being dependent on a single vari- able: $\Delta \mathbb{C} /[\mathbb{R} \cdot|F|]=\mathrm{AP}_{x}(\varsigma) / \ell(\varsigma)$. An analogous expression for DFCs is equal to the ratio $A / Q$ and independent of atmospheric stability. In Fig. $1 \mathrm{~b}, \Delta \mathbb{C} /[\mathbb{R} \cdot|F|]\left(\mathrm{h} \mathrm{m}^{-1}\right)$ is plotted as a function of stability for the flux measurement techniques inter-compared. For a given flux, it is imperative that the chamber methods have the mildest requirements for $\mathrm{Hg}^{0}$ sensor resolution. On the other hand, the analyzer requirements for all MM methods are most stringent under near-neutral conditions when the surface boundary layer is well mixed. The intensity of turbulent mixing declines with increasing atmospheric stability $(\varsigma)$, leading to higher concentration gradients. Among the MM methods, the analyzer requirement for gradient methods is least stringent for stable conditions (it should, however, be noted that large flux uncertainties under stable conditions could be encountered with the gradient method; Foken, 2008), while REA and gradient methods have nearly equivalent precision requirements under significant unstable conditions $(\varsigma<-0.1)$. With a profile measurement height ratio $\left(z_{2} / z_{1}\right)$ of $\sim 3.9$ in this study, the gradient methods are a favorable choice under most conditions, as REA requires greater analytical precision. However, flux measurements over tall vegetation, such a forest canopy, using gradient relationships become less favorable, e.g., due to the fact that $z_{2}$ must be chosen quite low according to fetch limitations, whereas the recommended minimum height of $z_{1}$ is confined to a fairly elevated level by issues like the extension of roughness sublayer and internal boundary layers. Over tall vegetation, typically $\left(z_{2}-d\right) /\left(z_{1}-d\right)$ $\sim 1.5$ can be achieved (Moravek et al., 2014).

\subsection{Analysis of flux bias and uncertainty}

\subsubsection{Dynamic flux chambers}

DFC measurement of $\mathrm{Hg}^{0}$ fluxes is potentially prone to a variety of errors. Aspects such as spatial representativeness (Gustin and Lindberg, 2000), chamber design, operation parameters (e.g., flushing flow rate) (Eckley et al., 2010; Lindberg et al., 2002; Lin et al., 2012), fabrication materials (e.g., quartz glass, FEP Teflon film, polycarbonate) (Carpi et al., 2007) and a modified microenvironment inside the chamber (e.g., increased temperature) should be considered. The flushing flow rate has been isolated as a key factor that can force a difference in measured flux up to 1 order of magnitude (Eckley et al., 2010). Other factors including solar radiation, soil temperature and soil moisture are also influential factors of $\mathrm{Hg}^{0}$ flux over soil (Lin et al., 2010). In turn, the modified temperature and radiation balance inside the DFC may lead to an erroneous quantification. In our assessment of the method bias of the TDFC and NDFC techniques, flushing flow rate was set at a fixed value for both DFCs and is therefore not considered as a variable. The soil moisture remained largely invariant during the campaign. Therefore, soil temperature $\left(T_{\text {soil }}\right)$ and irradiance $(S)$ were the key factors controlling the flux variability during IC no. 1 (Zhu et al., 
2015). We used a polynomial incorporating predictor terms up to quadratic order to fit the DFC flux with corresponding observations of $T_{\text {soil }}$ and $S$ inside the DFCs:

$$
\hat{F}_{\mathrm{DFC}}=\gamma_{0}+\gamma_{1} T_{\text {soil }}+\gamma_{2} S+\gamma_{3}\left(T_{\text {soil }} \cdot S\right)+\gamma_{4} T_{\text {soil }}^{2}+\gamma_{5} S^{2} .
$$

Predictive regression models are developed for each of the chamber types (Lin et al., 2010):

$$
\begin{aligned}
& \hat{F}_{\mathrm{NDFC}}=\left[-3.44-0.424 T_{\text {soil }}-0.017 S+\right. \\
& \left.0.003\left(T_{\text {soil }} \cdot S\right)+0.088 T_{\text {soil }}^{2}+9.02 \times 10^{-5} S^{2}\right] \cdot \frac{k_{\text {mass }(\mathrm{a})}}{k_{\text {mass }(\mathrm{m})}} \\
& \hat{F}_{\mathrm{TDFC}}=-3.977-1.05 T_{\text {soil }}-0.022 S+0.003\left(T_{\text {soil }} \cdot S\right) \\
& +0.072 T_{\text {soil }}^{2}+7.214 \times 10^{-5} S^{2}
\end{aligned}
$$

Overall fits (correlation coefficient, $R$ ) of 0.91 and 0.87 were obtained for NDFC and TDFC, respectively $(p<$ $0.001)$. Absolute bias $\left(\varepsilon_{\mathrm{DFC}}\right)$ of chamber-derived flux is estimated using

$\varepsilon_{\mathrm{DFC}}=\hat{F}_{\mathrm{DFC}}-\hat{F}_{N}+\varepsilon_{\text {blank }}$

In turn, as the flux calculated in Eq. (1), the uncertainty associated with TDFC measurements is estimated as

$\delta_{F}^{\mathrm{TDFC}}= \pm \sqrt{\left(\delta_{\Delta C_{\text {enclosure }}}^{\mathrm{IS}}\right)^{2}+\delta_{\Delta C_{\text {blank }}}^{2}} \cdot Q / A$

Concerning the NDFC approach, the uncertainty in the last term $\left(k_{\operatorname{mass}(\mathrm{a})} / k_{\operatorname{mass}(\mathrm{m})}\right)$ of Eq. (2) was incorporated into Eq. (11).

\subsubsection{Micrometeorological methods}

There are several errors in the MM flux measurements, especially for the REA technique. In general, the sources include source/sink characteristic (footprint variability), turbulent transport and instrumentation factors (Businger, 1986). Turbulent $\mathrm{Hg}^{0}$ fluxes determined by Eqs. (3)-(5) include parameters derived from OPEC flux, whose precision improves by a factor of $1 / \sqrt{t_{\text {average }}}$ by increasing the flux averaging time $\left(t_{\text {average }}\right)$. In this work, $t_{\text {average }}=20$ min was applied for all methods. For the assessment of $t_{\text {average, }}$ see Sommar et al. (2013b). The estimation of uncertainty in OPEC-derived parameters ( $H$ and $u_{*}$ ) is based on random sampling errors quantified as the variance of a covariance by the method of Finkelstein and Sims (2001). The conventional approach of investigate uncertainties from the bottom-up principle was applied.

\section{REA method}

Using error propagation theory on Eq. (3), uncertainties associated with the REA-derived fluxes can be calculated by
Eq. (12):

$$
\begin{aligned}
& \delta_{F}^{\mathrm{REA}} / F^{\mathrm{REA}}= \\
& \pm \sqrt{\left(\delta_{\sigma_{w}} / \sigma_{w}\right)^{2}+\left(\delta_{\beta} / \beta\right)^{2}+\left(\delta_{\Delta C_{\mathrm{REA}}} / \Delta C_{\mathrm{REA}}\right)^{2}} .
\end{aligned}
$$

However, the first term was demonstrated to give an insignificant contribution to the combined uncertainty (see Sect. 4.2). Excluding the contribution from $\sigma_{w}$, the number of independent quantities in Eq. (12) to be propagated for $\delta_{F}$ REA $/ F^{\text {REA }}$ is, according to Kramm et al. (1999), described by Eq. (13):

$\delta_{F}{ }^{\mathrm{REA}} / F^{\mathrm{REA}}=$
$\pm \sqrt{\left(\delta_{H} / H\right)^{2}+\left(\delta_{\Delta C_{\mathrm{REA}}} / \Delta C_{\mathrm{REA}}\right)^{2}+2\left(\delta_{\Delta T_{\mathrm{S}, \mathrm{REA}}} / \Delta T_{\mathrm{s}, \mathrm{REA}}\right)^{2}}$.

The REA system is potentially affected by lag-time bias and the attenuation of high-frequency concentration fluctuations in the tube flow that leads to an underestimation of turbulent fluxes. These effects were evaluated following Moravek et al. (2013) and the results are reported in Sect. 4.2. Theoretically, $\beta$ has negligible bias, since any bias in temperature and wind speed is virtually cancelled out during the calculation (Pattey et al., 1992; $\beta_{T_{\mathrm{S}}}$ derived from buoyancy heat flux):

$$
\begin{aligned}
\beta_{T_{\mathrm{s}}} & =\overline{w^{\prime} T_{\mathrm{s}}^{\prime}} /\left[\sigma_{w} \cdot\left(\overline{T_{\mathrm{s}}^{\uparrow}}-\overline{T_{\mathrm{s}}^{\downarrow}}\right)\right] \\
& =\overline{w^{\prime} T_{\mathrm{s}}^{\prime}} /\left(\sigma_{w} \cdot \Delta T_{\mathrm{s}, \mathrm{REA}}\right) .
\end{aligned}
$$

In practice, bias exists due to departures from a 0 mean vertical wind speed $(\bar{w})$ during the flux averaging period. The present REA application allowed for the rejection of samples associated with $w$ fluctuations around 0 ("deadband", DB). Consequently, $C^{\uparrow}$ is sampled only for $w>w_{\mathrm{DB}}$ and $C^{\downarrow}$ only for $w<-w_{\mathrm{DB}}$ (Eq. 3), which also applies for $T_{\mathrm{s}}^{\uparrow}$ and $T_{\mathrm{s}}^{\downarrow}$ (Eq. 14). A 5 min moving average filter combined with a deadband based on a ditto moving standard deviation $\left(\overline{w_{5^{\prime}}}-0.3 \cdot \overline{\sigma_{w, 5^{\prime}}}<\mathrm{DB}<\overline{w_{5^{\prime}}}+0.3 \cdot \overline{\sigma_{w, 5^{\prime}}}\right)$ was implemented in the REA program aiming during sampling to alleviate for $\bar{w}$ bias from the $w$ signal. Nevertheless, the effectiveness of various applied filter techniques appears largely ambiguous (Bowling et al., 1998). To investigate residual bias in the selected conditional sampling scheme, $\beta_{T_{\mathrm{s}}}$ derived online was compared with $\beta_{T_{\mathrm{s}}}$ calculated from the a posteriori known $\overline{w_{20^{\prime}}}$ and $\overline{\sigma_{w, 20^{\prime}}}$ using the filter $\overline{w_{20^{\prime}}}-0.3 \cdot \overline{\sigma_{w, 20^{\prime}}}<\mathrm{DB}<$ $\overline{w_{20^{\prime}}}+0.3 \cdot \overline{\sigma_{w, 20^{\prime}}}$ to numerically segregate temperature data into updraft and downdraft bins representative of $t_{\text {average. The }}$ result is reported in Sect. 4.2.

\section{Gradient-based methods}

The AGM flux is computed as the product of transfer velocity $\left(v_{\text {tr }}\right)$ and vertical $\mathrm{Hg}^{0}$ concentration gradient $\left(\Delta C_{\text {grad. }}\right)$. In 
Eq. (4), $v_{\text {tr }}$ is compounded from multiple independent quantities. Following Wolff et al. (2010), the relative uncertainty in $F^{\mathrm{AGM}}$ can be calculated according to

$\delta_{F^{\mathrm{AGM}}} / F^{\mathrm{AGM}}=$

$\pm \sqrt{\left(\delta_{\Delta C_{\text {grad. }}} / \Delta C_{\text {grad. }}\right)^{2}+\left(\delta_{u_{*}} / u_{*}\right)^{2}+\left(\delta_{\psi_{H}} / \psi_{H}\right)^{2}\left(\frac{\left(\psi_{H}\left(\varsigma_{2}\right)+\psi_{H}\left(\varsigma_{1}\right)\right)^{2}}{\left(\ln \left(z_{2} / z_{1}\right)-\psi_{H}\left(\varsigma_{2}\right)+\psi_{H}\left(\varsigma_{1}\right)\right)^{2}}\right)}$.

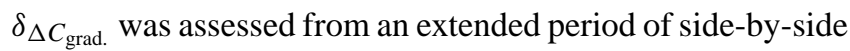
measurements (Sect. 3.2). Friction velocity $\left(u_{*}\right)$ is derived from OPEC measurements of momentum flux $\left(\tau=\rho \cdot u_{*}^{2}\right)$. Assuming insignificant uncertainties in the air density determination, we obtain $\delta_{u_{*}} / u_{*}=\frac{1}{2} \cdot \delta_{\tau} / \tau$ to insert into Eq. (15). For the right-hand compounded term of Eq. (15), we assumed that the uncertainty in $\psi_{H}$ is similar to that of the universal function (Foken, 2008), which is generally better than $10 \%$. For near-neutral stability conditions, it becomes confined to a few percent (Garratt and Taylor, 1996). To resolve this, we choose to use a simplistic approach, where $\delta_{\psi_{H}} / \psi_{H}$ is scaled with the aerodynamic stability by intervals (for $\left|\varsigma_{2}\right|<0.1, \delta_{\psi_{H}} / \psi_{H}=0.02$, for $\left|\varsigma_{2}\right|>0.5$, $\delta_{\psi_{H}} / \psi_{H}=0.10$, and for the ranges in-between, a linear interpolation was applied).

The relative uncertainty in $F^{\mathrm{MBR}}$ measurements is calculated by

$\delta_{F^{\mathrm{MBR}}} / F^{\mathrm{MBR}}=$

$\pm \sqrt{\left(\delta_{H} / H\right)^{2}+\left(\delta_{\Delta C_{\text {grad. }}} / \Delta C_{\text {grad. }}\right)^{2}+\left(\delta_{\Delta T_{\text {grad. }}} / \Delta T_{\text {grad. }}\right)^{2}}$.

Similar to the assessment of $\delta_{\Delta C_{\text {grad. }}} / \Delta C_{\text {grad. discussed }}$ in Sect. 3.2, $\delta_{\Delta T_{\text {grad. }}} / \Delta T_{\text {grad. }}$ is derived from collocated duplicate thermocouple measurements of air temperature.

\section{Experimental results}

The uncertainty in concentration measurements of the three collocated Tekran 2537Bs was calculated from the uncertainty in volume and calibration measurements. Sample volumes derived from independent techniques are found to be within $\pm 0.5 \%$ of the $2537 \mathrm{~B}$ volume readings. The uncertainty in concentration measurement is mainly contributed by field calibrations. The combined uncertainty is estimated to be $\pm 5 \%$. This compares favorably with the agreement among these $2537 \mathrm{~B}$ instruments $(< \pm 6 \%)$ during side-byside measurements with a common inlet sampling $\mathrm{Hg}^{0}$ in ambient air.

\subsection{Bias and uncertainty in DFC-derived $\mathrm{Hg}^{\mathrm{0}}$ fluxes}

Field blanks determined in connection with regular flux measurement periods were consistently low for both DFCs (TDFC: $0.2 \pm 0.1 \mathrm{ng} \mathrm{m}^{-2} \mathrm{~h}^{-1}, n=19$; NDFC: $0.3 \pm 0.2 \mathrm{ng} \mathrm{m}^{-2} \mathrm{~h}^{-1}, n=32$ ). Bias of DFC-derived flux as estimated using Eqs. (8)-(10) was in the ranges of -0.6
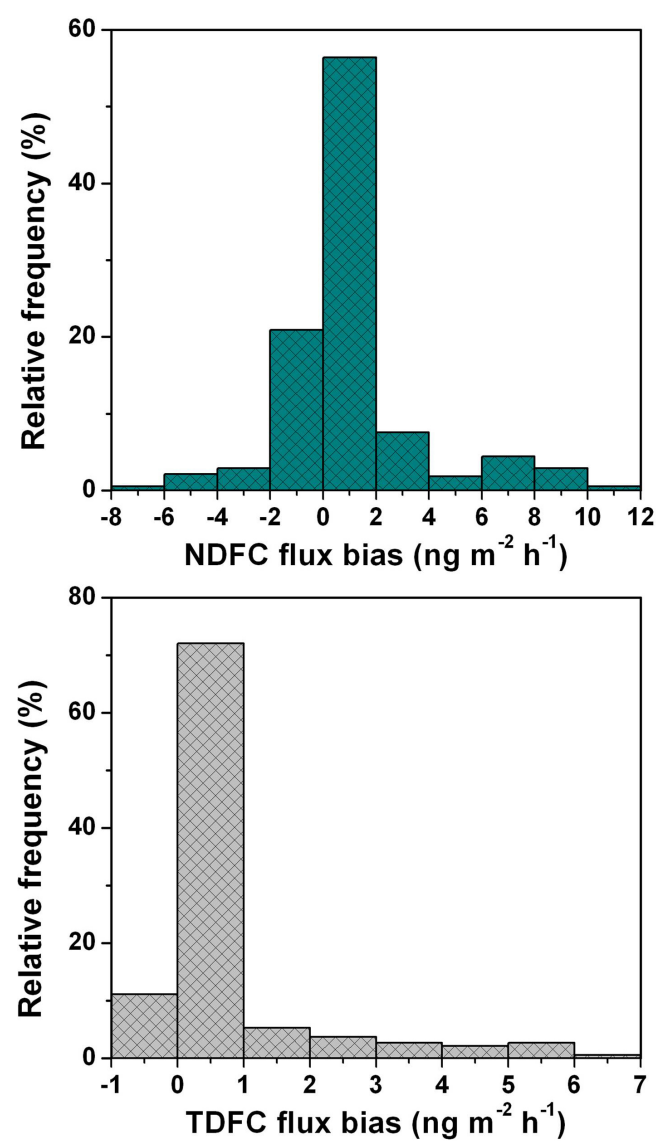

Figure 2. Frequency distribution of DFC flux bias $\left(\varepsilon_{\mathrm{DFC}}\right)$ for TDFC and NDFC methods during IC no. 1.

to 6.7 and from -7.2 to $10.6 \mathrm{ng} \mathrm{m}^{-2} \mathrm{~h}^{-1}$ for TDFC and NDFC, respectively (Fig. 2). The median bias for both DFCs was slightly positive $\left(0.1\right.$ and $0.2 \mathrm{ng} \mathrm{m}^{-2} \mathrm{~h}^{-1}$ for TDFC and NDFC). In both cases, more than $85 \%$ of the flux observations had a bias of $<2 \mathrm{ng} \mathrm{m}^{-2} \mathrm{~h}^{-1}$ in magnitude. Possible reasons for the data disparity include (1) the difference in the light transmission properties of the two chamber materials, and (2) the difference in soil temperature inside the chamber. The TDFC was manufactured from quartz glass, while the NDFC was assembled from polycarbonate (PC) sheets (Lin et al., 2012; Zhu et al., 2013b, 2015). Quartz has exceptional transmission properties for UV light down to $250 \mathrm{~nm}$, while PC does not allow transmission of UV light that plays an important role in promoting $\mathrm{Hg}^{\mathrm{II}}$ photo-reduction in the substrate (Eckley et al., 2010; Lin et al., 2012). The heating of the soils inside the two chambers was also different (soil temperature difference between the inside and outside of the chamber were up to 3.8 and $4.7^{\circ} \mathrm{C}$ for $\mathrm{TDFC}$ and NDFC) because of the difference in chamber materials, dimensions and air exchange rates $\left(\sim 3.1\right.$ and $\sim 2.1 \mathrm{~min}^{-1}$ for TDFC and NDFC). Consequently, DFCs flux bias showed diurnal cycles with positive bias in the afternoon due to the fact that soil temperature change considerably lags behind that 

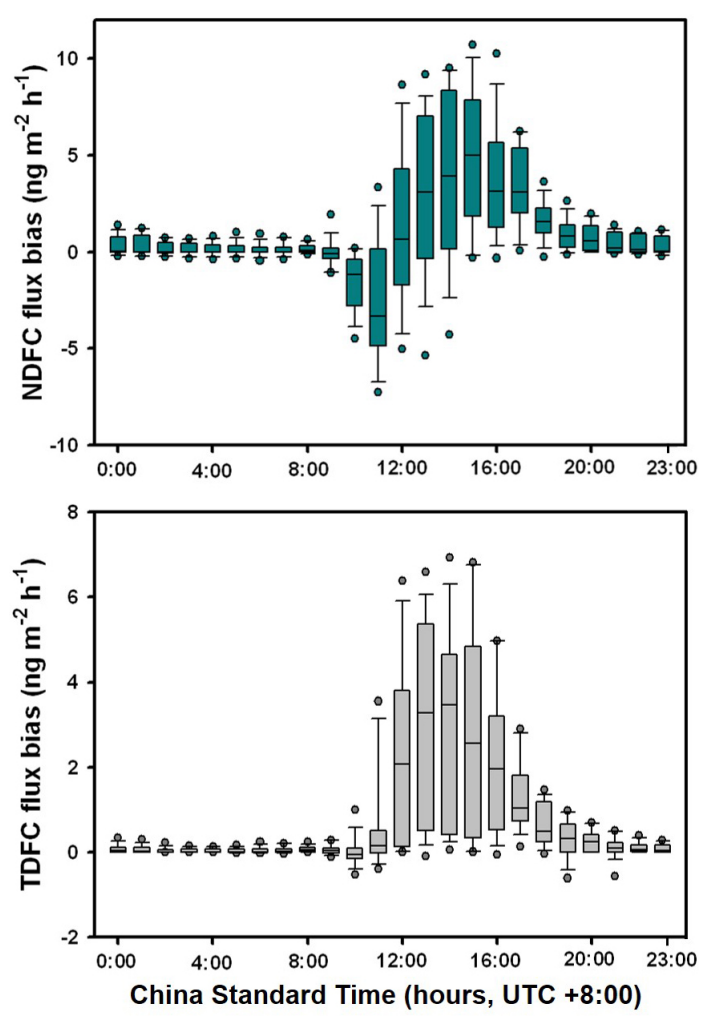

Figure 3. Box-whisker plots of diurnal flux bias measured with two DFCs. The box boundaries represent 25 th and 75 th percentiles from bottom to top, and whiskers indicate 10th and 90th percentiles of $\mathrm{Hg}^{0}$ flux. Line in the box and plots out of the whiskers indicate the mean and bias threshold.

of air temperature (Fig. 3). Discernible negative flux bias in NDFC flux appeared from 10:00 to 11:00 a.m. due to weaker light transmission caused by water condensation that lowered $\mathrm{Hg}^{0}$ emission. Following Eq. (11), the maximum uncertainty in TDFC-derived flux ( $\left.\delta_{F} \mathrm{TDFC}\right)$ was estimated to be $\pm 2.8 \mathrm{ng} \mathrm{m}^{-2} \mathrm{~h}^{-1}$. For typical daytime conditions $\left(\delta_{u_{*}} / u_{*}<\right.$ $\pm 5 \%$, Sect. 4.3 ), $\delta_{F^{\mathrm{NDFC}}}$ was within $\pm 2.1 \mathrm{ng} \mathrm{m}^{-2} \mathrm{~h}^{-1}$, similar to $\delta_{F \mathrm{NDFC}}$ (Table 1). For nocturnal conditions, the uncertainty level is similar to the measured fluxes.

\subsection{Bias and uncertainty in REA-derived $\mathrm{Hg}^{0}$ fluxes}

The lag-time bias due to unsynchronized conditional sampling (Baker et al., 1992) is estimated at $\pm 25 \mathrm{~ms}$ as an upper limit based on logged fluctuations of the flow rate in the intake tube upstream of the REA segregator valves corresponding to attenuation of a $\mathrm{Hg}^{0}$-REA flux of at most $2 \%$ (Moravek et al., 2013). Likewise, flux loss due to dampening of sampled high-frequency concentration fluctuations in the section is small. The flow regime in the intake line is turbulent $(R e \sim 3500)$ and the smallest fluctuations in air are in fact not sampled, since a DB is applied. The insignificant

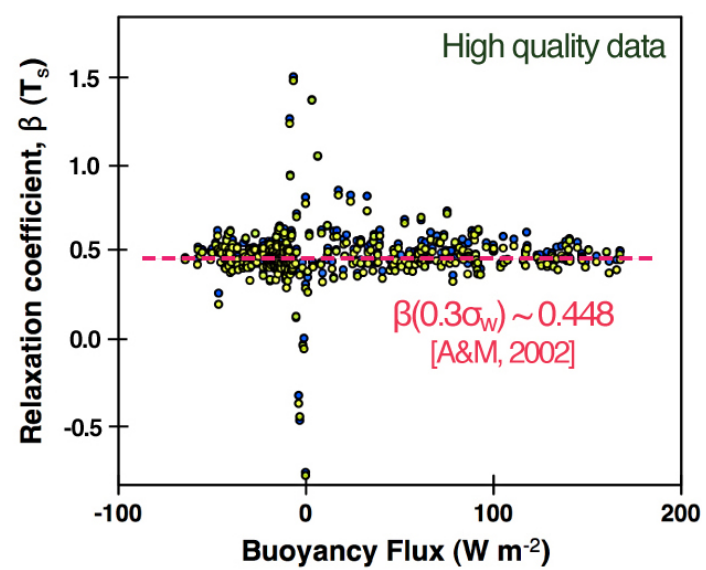

Figure 4. Scatterplot of the $\beta_{T}$ factor derived from actual REA sampling (filled blue circles) and from a posteriori offline synthesis (filled yellow circles) versus buoyancy heat flux. The inlaid line (magenta-colored) represents the predicted $\beta(0.448)$ for a dynamic deadband discrimination factor of 0.3 (Ammann and Meixner, 2002).

magnitude of these negative biases occasioned no action in the form of flux corrections.

The evaluation of the effectiveness of the applied conditional sampling filter (Sect. "REA method") is applied to data flagged for high-quality turbulence (Flag $0, \sim 72 \%$ of the IC no. 2 duration). This procedure yielded an estimate of "unbiased" $\beta_{T_{\mathrm{S}}}$. It is found that the median of the online and "unbiased" $\beta_{T_{\mathrm{s}}}$ factor differed significantly (Mann-Whitney $\mathrm{U}$ test, $n=378, p<0.01)$ from the former higher one $(0.486$ versus 0.439 ) (Fig. 4). Accordingly, the online-derived $\beta_{T_{\mathrm{s}}}$ tend to overestimate flux by $\sim 10 \%$ on average (Table 1 ). The median of resampled $\beta_{T_{\mathrm{s}}}$ is closer to the value 0.448 $(-2<\varsigma<0.06)$ predicted from the relationship given by Amman and Meixner (2002). The a posteriori calculated $\beta_{T_{\mathrm{s}}}$ is used to calculate individual turbulent REA flux for Flag 0 data. A fixed $\beta_{T_{\mathrm{s}}}$ of 0.45 is implemented for the remaining periods (Flags 1 and 2) or if the a posteriori $\beta_{T_{\mathrm{s}}}$ is outside a \pm 0.2 interval of the median (Schade and Goldstein, 2001).

The relative uncertainty in $\sigma_{w}\left(\delta_{\sigma_{w}} / \sigma_{w}\right)$ of Eq. (12) is estimated as an upper limit using $\delta_{w}^{2} / \sigma_{w}^{2}(\mathrm{Xu}, 2001)$. According to CSAT-3 specification, the absolute uncertainty of a single measurement of vertical wind $\left(\delta_{w}\right)$ is $0.5 \mathrm{~mm} \mathrm{~s}^{-1}$. Concerning class 0 and 1 data, $\delta_{w}^{2} / \sigma_{w}^{2}$ was, for $\sim 98 \%$ of the $20 \mathrm{~min}$ integrated measurements, $\leq 1 \%$. Consequently, Eq. (13) was adopted to assess the relative uncertainty in $F^{\text {REA }}$. In Fig. 5, the argument in the first term $\left(\delta_{H} / H\right)$ in Eq. (13) segregated into turbulent quality classes is plotted versus the corresponding flux for IC no. 2. When $H$ flux changes sign or diminishes to near 0 at dawn/dusk and during the night, there is a significant increase in $\delta_{H} / H$. Concerning the data classified with high quality and $|H|>20 \mathrm{~W} \mathrm{~m}^{-2}$, the distribution of $\delta_{H} / H$ is narrow 
Table 1. Estimated $\mathrm{Hg}^{0}$ flux bias and uncertainties in inter-compared DFCs and MM flux measurement techniques.

\begin{tabular}{|c|c|c|c|c|}
\hline \multirow[t]{2}{*}{ Methods } & \multirow[t]{2}{*}{ Sources of errors } & \multirow[t]{2}{*}{ Flux bias } & \multicolumn{2}{|c|}{ Flux uncertainty } \\
\hline & & & IC no. 1 & IC no. 2 \\
\hline \multirow[t]{6}{*}{ REA } & $\begin{array}{l}\text { Inadequacy of online filtering of the } w \text { signal } \\
\text { from } \bar{w} \text { bias }\end{array}$ & Overestimated: $9.7 \% \pm 14.5 \%$ & & \\
\hline & $\begin{array}{l}\text { Sensor separation, lag time and smearing of } \\
\text { conditionally sampled eddies }\end{array}$ & Underestimated: $<2 \%$ & & \\
\hline & Sensible heat flux measurement & & & $9.9 \pm 12.7 \%$ \\
\hline & Conditional sampling channels & Overestimated: $5.1 \%$ & & $7.9 \pm 6.6 \%$ \\
\hline & Intermittent conditional sampling & & & $13.7 \pm 17.0 \%$ \\
\hline & Conditional sampled sonic temperature & & & $2.7 \pm 1.9 \%$ \\
\hline \multirow[t]{4}{*}{ MBR } & Concentration gradient sampling & Underestimated: $4.1 \%$ & $7.2 \pm 6.2 \%$ & $6.2 \pm 4.6 \%$ \\
\hline & Intermittent sampling of conc. gradient & & $4.6 \pm 11.3 \%$ & $4.6 \pm 12.3 \%$ \\
\hline & Sensible heat flux & & $18.0 \pm 49.7 \%$ & $9.9 \pm 12.7 \%$ \\
\hline & Temperature gradient & & $\leq 0.4 \%$ & $\leq 0.4 \%$ \\
\hline \multirow[t]{4}{*}{ AGM } & Concentration gradient sampling & Underestimated: $4.1 \%$ & $7.2 \pm 6.2 \%$ & $6.2 \pm 4.6 \%$ \\
\hline & Intermittent sampling of conc. gradient & & $4.6 \pm 11.3 \%$ & $4.6 \pm 12.3 \%$ \\
\hline & Friction velocity & & $9.1 \pm 10.6 \%$ & $5.5 \pm 5.6 \%$ \\
\hline & Transfer velocity & & $10.9 \pm 12.6 \%$ & $6.1 \pm 10.2 \%$ \\
\hline \multirow[t]{2}{*}{ NDFC } & Micro-environmental effect & -7.2 to $10.6 \mathrm{ng} \mathrm{m}^{-2} \mathrm{~h}^{-1}$ & & \\
\hline & Intermittent sampling & & $2.1 \mathrm{ng} \mathrm{m}^{-2} \mathrm{~h}^{-1}$ & \\
\hline \multirow[t]{2}{*}{ TDFC } & Micro-environmental effect & -0.6 to $6.7 \mathrm{ng} \mathrm{m}^{-2} \mathrm{~h}^{-1}$ & & \\
\hline & Intermittent sampling & & $2.8 \mathrm{ng} \mathrm{m}^{-2} \mathrm{~h}^{-1}$ & \\
\hline
\end{tabular}

Notes: for MM techniques, bias and uncertainties are given as fractional values (percent) of the flux representing the median $\pm 1.48 \times$ IQR, while for the enclosure techniques, the absolute values are given.

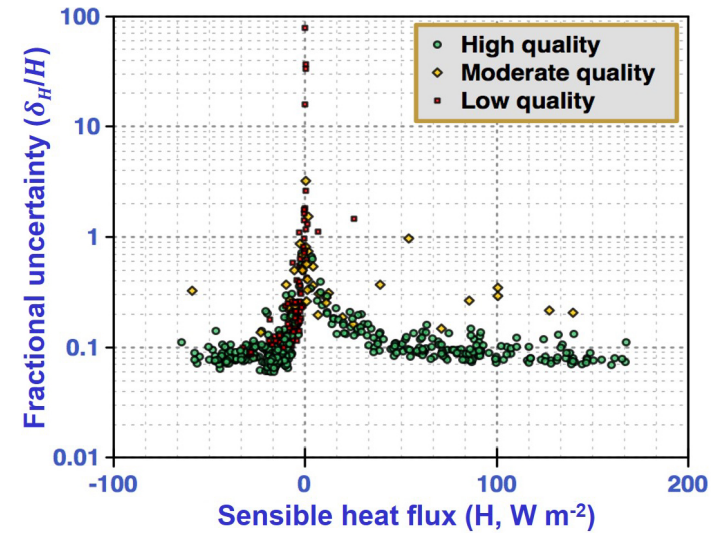

Figure 5. Scatterplot of fractional uncertainty in sensible heat flux $\left(\delta_{H} / H\right)$ segregated into turbulence quality classes (Mauder and Foken, 2004) versus the corresponding flux during IC no. 2.

$(9.9 \pm 12.7 \%$, IC no. 2, Table 1). The result is in agreement with other studies (Walker et al., 2006; Finkelstein and Sims, 2001). In comparison with IC no. 2, IC no. 1 included a larger proportion of turbulence data with poor quality (see Fig. 4 in Zhu et al., 2015), contributing to a higher overall uncertainty in $\delta_{H} / H$ (Table 1).
The uncertainty and bias in $\Delta C_{\text {REA }}$ was deduced from periods of reference sampling covering a representative span of ambient $\mathrm{Hg}^{0}$ concentrations $\left(\sim 1.5-8.1 \mathrm{ng} \mathrm{m}^{-3}\right)$. The asynchronous collected channel data were cross-interpolated to simulate concurrent $\mathrm{Hg}^{0}$ gas analysis of the two channels. This data set is assessed using orthogonal linear regression assuming equal variances for the channels, which is more appropriate than defining one as independent, as in standard least-square methods (Cantrell, 2008). A scatterplot aligns well with a line of slope 1.051 and a non-significant $(p=$ 0.22 ) offset from 0 (Fig. 6). Hence, there exists a moderate bias between the channels, which is corrected in Table 1 . Such regular performance tests are very infrequently reported in the REA literature (Arnts et al., 2013; Hensen et al., 2009; Park et al., 2010; Schade and Goldstein, 2001). Significant and variable REA channel biases were occasionally detected (Nemitz et al., 2001; Schade and Goldstein, 2001). In this study, the time series of reference sampling covering both day and night periods do not reveal any significant diurnal pattern or trend over the time to proceed.

Inspection of residuals of the orthogonal fit plotted as a function of sampling time (record number) showed homoscedastic features. In Fig. 7, the residuals that approximately align with a Gaussian distribution are plotted as a function of $\mathrm{Hg}^{0}$ concentration in ambient air. Following 


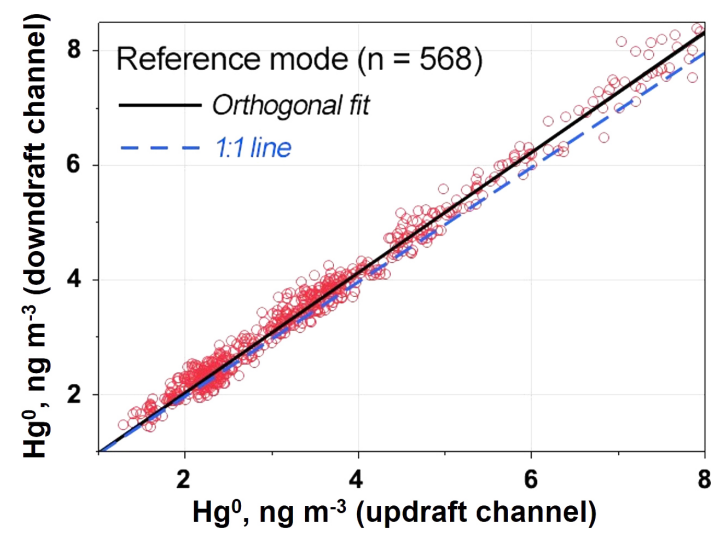

Figure 6. Results from conditional channel inter-comparison using the REA reference sampling mode (slope: 1.051; intercept: -0.012 ). The $1: 1$ slope was inlaid with the orthogonal linear fit.

Wolff et al. (2010) and Walker et al. (2013), we used the standard deviation of the residuals as a measure of $\delta_{\Delta C_{\mathrm{REA}}}^{\text {channel }}$. The absolute uncertainties $\left|\delta_{\Delta C_{\mathrm{REA}}}^{\text {channel }}\right|$ were found to be a variant of air concentration and were fitted to a linear function by regression. The resulting function of $\delta_{\triangle C_{\mathrm{REA}}}^{\text {channel }}=0.069+0.022 C$ was used to predict the $\Delta C_{\mathrm{REA}}$ detection limit for each flux observation and in the uncertainty propagation of Eq. (13) (see Table 1). Uncertainty due to the intermittent conditional sampling $\left(\delta_{\Delta C_{\mathrm{REA}}}^{\mathrm{IS}}\right)$ was approached by assessing the concentration difference between bias-corrected conditional (10 min) and corresponding $20 \mathrm{~min}$ average concentrations as a function of the fractional difference between previous and following same conditional line concentrations (Walker et al., 2006). The corresponding median relative uncertainty was $13.7 \%$, but the data set includes transition periods, where individual values rise to well over $50 \%$. The calculations of $\delta_{\Delta C_{\mathrm{REA}}}$ likely represent an upper limit, since the estimate of uncertainty due to intermittent sampling includes contributions due to analytical precision.

The last term in Eq. (13) was assessed from the sonic temperature measurement resolution (root mean square) of $0.025 \mathrm{~K}$ for standard settings of CSAT- $3\left(\delta_{T_{\mathrm{s}}}\right.$, single measurement). An upper limit of $\delta_{\Delta T_{\mathrm{s}, \mathrm{REA}}} / \Delta T_{\mathrm{s}, \mathrm{REA}}$ is given by $\frac{\delta_{\Delta T_{\mathrm{S}}}}{\Delta T_{\mathrm{S}, \mathrm{REA}}} \cdot \sqrt{\frac{2}{m}}$, where $m$ is the number of measurements per flux averaging period (i.e., $m=12000)(\mathrm{Xu}, 2001)$. Due to the bidirectional nature of buoyancy heat flux, when $\Delta T_{\mathrm{s}, \mathrm{REA}}$ changes sign or approaches near-zero at dawn, dusk, and intermittently during night, $\delta_{\Delta T_{\mathrm{s}, \mathrm{REA}}} / \Delta T_{\mathrm{s}, \mathrm{REA}}$ attains values above the sub-percent level that it is normally present in. For high turbulence quality segregated data, the $\Delta T_{\mathrm{S}, \mathrm{REA}}$ relative uncertainty was calculated to $0.8 \pm 0.5 \%$.

\subsection{Bias and uncertainty in gradient-derived $\mathrm{Hg}^{\mathbf{0}}$ fluxes}

The primary bias in the MBR and AGM flux is caused by the potential sampling artifact for determining concentra-

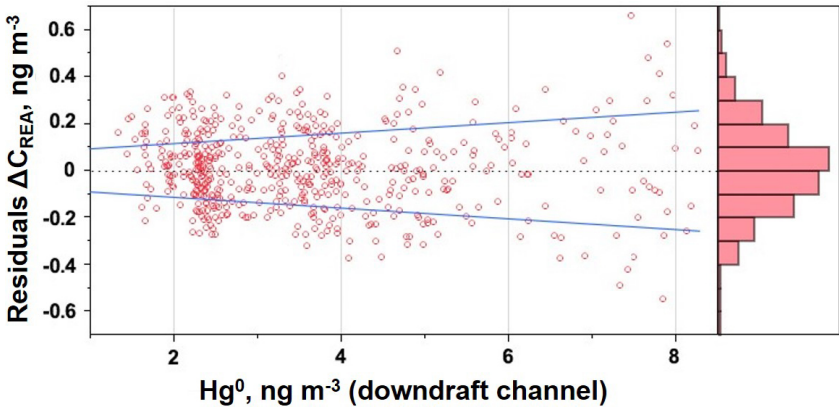

Figure 7. Histogram of residuals obtained after correcting the channel data for bias with orthogonal linear regression (right). Scatterplot of residuals versus $\mathrm{Hg}^{0}$ concentration (indicated by the predicted concentration of the downdraft channel). The blue lines (uncertainty range around 0 ) are derived from linear regression of the moduli of residuals.

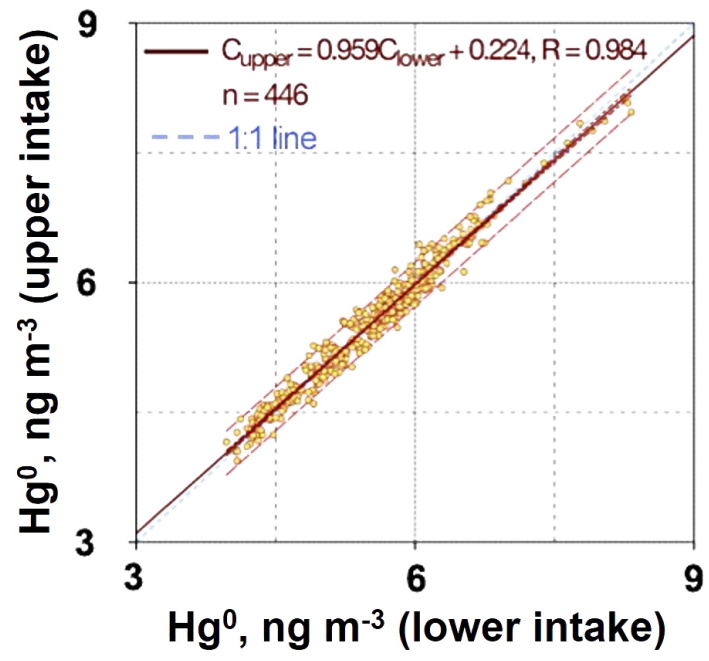

Figure 8. Scatterplot of concentrations from lower and upper level sampling lines during side-by-side measurement. The linear fit derives from orthogonal regression. The 1 : 1-relationship and $95 \%$ prediction intervals are indicated by dashed lines (light blue and red colors, respectively).

tion gradients. Extended periods of side-by-side measurements (gas sampling inlets were brought to one height in the same lateral proximity as during regular gradient sampling) were conducted. The comparison between the collocated lines used for two-level gradient sampling is based on sequential concentration data. For a further investigation, cross-interpolation was used as an imputation method to fill up missing values in the time-concentration series. Orthogonal linear regression indicated that a bias existed between the sampling lines (Fig. 8), where the longer sampling tube (upper level) is biased low by $4.1 \%$. The remaining scatter (residual) distribution followed a Gaussian distribution and was homoscedastic with respect to sampling time and concentration. Hence, $\left|\delta_{\Delta C_{\text {grad. }}}^{\text {chanel }}\right|$ is largely invariant to $C$. The ab- 


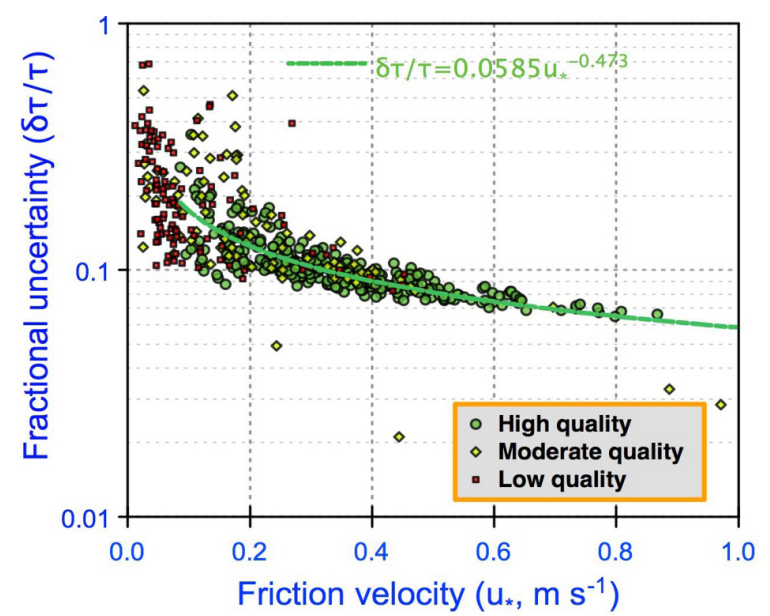

Figure 9. Relationship between fractional uncertainty in momentum flux $(\tau)$ and friction velocity $\left(u_{*}=\sqrt{\tau / \rho}\right)$ for turbulence quality segregated data.

solute uncertainty was estimated to be $0.064 \mathrm{ng} \mathrm{m}^{-3}$ based on the overall standard deviation of the residuals remaining after orthogonal linear regression. The corresponding relative bias for the median ambient $\mathrm{Hg}^{0}$ concentration during the campaigns is at $2.2 \%$. The uncertainties due to intermittent sampling of the concentration gradient $\left(\delta_{\Delta C_{\text {grad. }}}^{I S}\right)$ were assessed in an analogous way to that aforementioned for REA. The fractional uncertainty in $\Delta C_{\text {grad. }}$ due to a non-stationary $\mathrm{Hg}^{0}$ concentration is at $8.6 \%$ (median), with a corresponding median absolute deviation of $7.3 \%$.

Individual $\delta_{\tau} / \tau$ was estimated (Finkelstein and Sims, 2001) and plotted versus $u_{*}$ in Fig. 9. The overall scatter is substantial. However, the flag 0 data can favorably be approximated by a power relationship $\left(0.058 \cdot u_{*}^{-0.473}\right.$, $r=0.89$ ). For the mean $u_{*}$ of $0.3 \mathrm{~m} \mathrm{~s}^{-1}$ during the campaigns, the predicted fractional uncertainty is $\sim 5 \%$ and decreases slightly for the highest wind forces. For near-neutral stability conditions, $\delta_{v_{\text {tr }}} / v_{\text {tr }}$ was estimated to $10.9 \pm 12.6 \%$ and $6.1 \pm 10.2 \%$ for IC no. 1 and IC no. 2 (Table 1). Side-byside measurements of the HMP 155A sensors deployed for deriving $\Delta T_{\text {grad. }}$ in Eq. (5) indicated minor scale and offset bias in their performance, which was corrected for calculation. Analysis of residuals indicated that $\delta_{\Delta T_{\text {grad. }} / \Delta T_{\text {grad. }} \text { is }}$ diminutive $(\sim 0.4 \%)$ to the other terms in Eq. (16) (Table 1$)$.

\subsection{Turbulent flux measurements under varying experimental conditions}

Based on the $\Delta C$ detection limit $(1 \sigma)$ derived from sideby-side measurements (gradient method) and reference sampling (REA), $\sim 62 \%$ of the 20 min averaged gradient measurements were above this limit during IC no. 1, whereas during IC no. 2, $\sim 57$ and $\sim 55 \%$ of the concentration difference derived from gradient and REA sampling were above the limit. The empirically derived detection limit for $\Delta C_{\mathrm{REA}}$ was

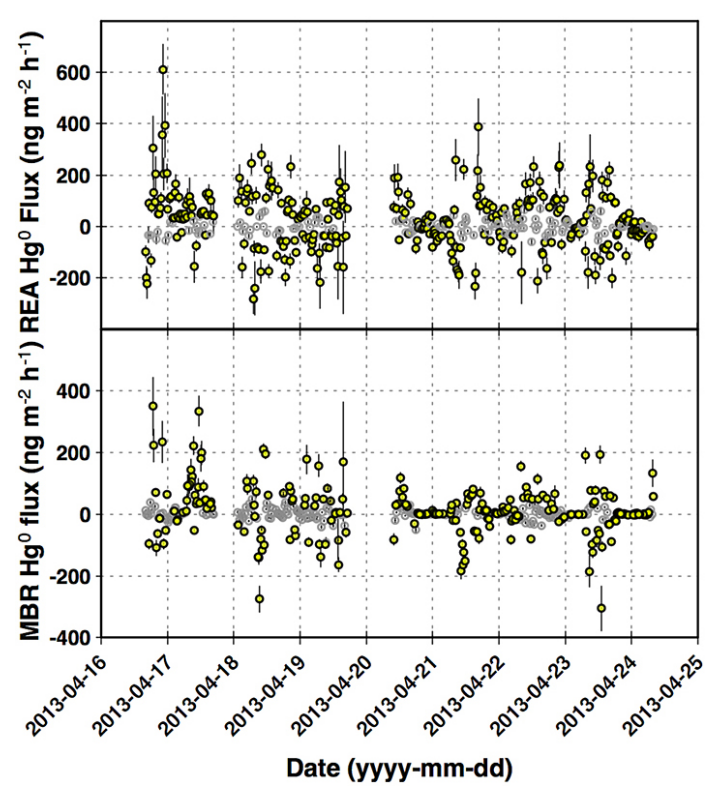

Figure 10. Turbulent $\mathrm{Hg}^{0}$ fluxes measured by the REA (upper panel) and the MBR (lower panel) technique during the second inter-comparison campaign. Error bars denote flux uncertainties derived from the analysis. The open grey circles represent $\mathrm{Hg}^{0}$ fluxes that are made up of $\Delta C_{\mathrm{REA}}$ and $\Delta C_{\text {grad. }}$ falling below their respective $1 \sigma$ detection limit.

moderately concentration dependent, while that of $\Delta C_{\text {grad. }}$ is found to be insignificantly variant. Since $\mathrm{Hg}^{0}$ air concentration at this site generally followed pronounced diurnal patterns (Part I, Zhu et al., 2015), the $\Delta C_{\mathrm{REA}}$ detection limit was on average $10-15 \%$ higher during the peak in the late morning hours compared to the minimum level. $\mathrm{Hg}^{0}$ flux observations can be identified as insignificant from 0 when the corresponding $\Delta C$ fall below its detection limit. Figure 10 shows the turbulent flux of REA and MBR time series with data segregated as significant and insignificant according to this analysis for the IC no. 2 period.

The level of the detection limit obtained in this study $\left(0.064 \mathrm{ng} \mathrm{m}^{-3}\right)$ compares favorably with the $0.072 \mathrm{ng} \mathrm{m}^{-3}$ reported by Converse et al. (2010) using gradient-based MM techniques. Compared to other studies deriving $\mathrm{Hg}^{0}$ gas exchange flux from concentration profile measurements (Edwards et al., 2005; Fritsche et al., 2008; Lee et al., 2000; Goodrow et al., 2005), our $\Delta C_{\text {grad. precision }}(1 \sigma)$ is contrastingly elevated, likely due to the generally higher level of ambient $\mathrm{Hg}^{0}$ concentration in this study (Zhu et al., 2015). The limited information existing in the literature regarding measurement of $\mathrm{Hg}^{0}$ flux by the REA technique (Bash and Miller, 2008; Cobos et al., 2002; Bash and Miller, 2009; Olofsson et al., 2005) excludes a rudimentary analysis and discussion of uncertainty and bias associated with conditionally sampled concentration differences.

Table 1 summarizes the uncertainty in MM and DFC flux methods in our inter-comparison. The relative uncertainties 


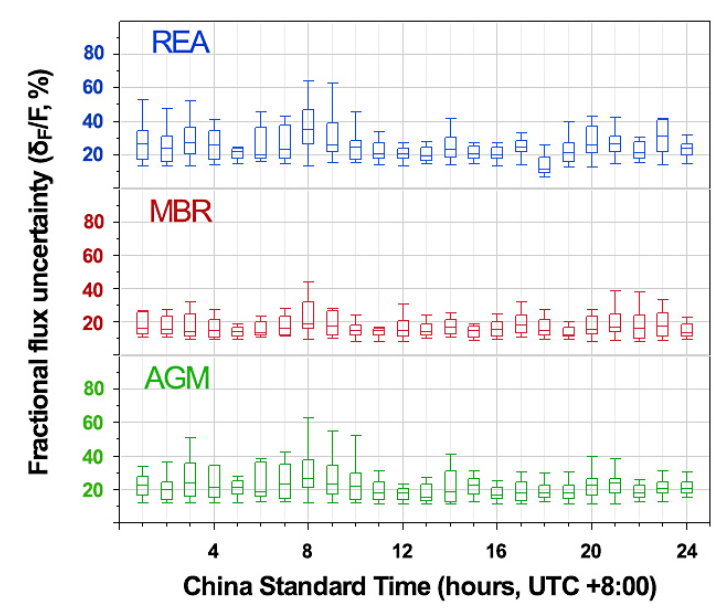

Figure 11. Box-whisker plots of the hourly fractional flux bias $\left(\delta_{F} / F\right)$ estimated for MM techniques inter-compared during IC no. 2. Boxes encompass the interquartile range (IQR, 25th to 75 th quantiles) and the horizontal line within the median value. The length of a whisker is 1.5 times that IQR.

for transfer velocity and sensible heat flux in IC no. 1 have nearly doubled (on a median basis) compared to those in IC no. 2 due to its lower turbulence quality. The uncertainty estimates associated with EC sampling errors based on the variance analysis of covariance time series (Finkelstein and Sims, 2001) used in this study are expected to be somewhat larger than calculations based on side-by-side comparisons or paired observations (Mauder et al., 2013). However, the latter type of estimate concerning uncertainties in concentration difference measurements is provided here as an upper limit. Median $\delta_{F} / F$ was slightly higher for the MBR compared to the AGM technique during IC no. 1 ( $\sim 24 \%$ versus $\sim 19 \%$ ), while the opposite condition was present during IC no. $2(\sim 15 \%$ versus $\sim 19 \%)$. For comparison of the three MM techniques during IC no. 2, the relative flux uncertainty $\left(\delta_{F} / F\right)$ is slightly higher during night-time (median $\sim 17$, $\sim 20$ and $\sim 25 \%$ for the MBR, AGM and REA techniques). Figure 11 shows the diurnal pattern of the MM technique $\delta_{F} / F$ during IC no. 2. A marked maximum is visible for the gradient-based as well as the REA technique during the hour after sunrise. This period is characterized by a transition in the sign of sensible heat flux and vertical temperature in addition to a generally rapid increase in $\mathrm{Hg}^{0}$ air concentration, while transfer velocities have not yet started to increase significantly from night-time low values (generally $<0.10 \mathrm{~m} \mathrm{~s}^{-1}$ ).

For most of the IC no. 2 periods, $\delta_{F}$ is primarily governed by $\delta_{\Delta C}$ (overall $\sim 60 \%$ median contribution for the REA and $\sim 52-56 \%$ for the gradient techniques). The uncertainties in REA sampling were on average higher than those during MBR/AGM operation, and the percentage of flux data below the corresponding $\Delta C$ detection limit is slightly larger for REA (Fig. 10). In turn, the turbulent $\mathrm{Hg}^{0}$ fluxes derived by

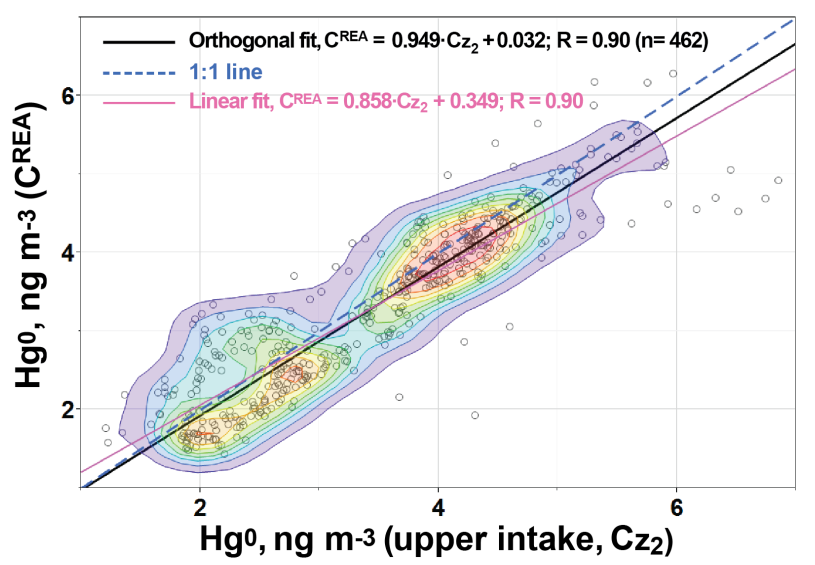

Figure 12. Linear regression of the $\mathrm{Hg}^{0}$ concentrations measured by the REA system ( $C^{\mathrm{REA}}$ ) versus the concentrations measured by the concentration gradient upper intake $\left(C_{Z_{2}}\right)$ at the same height $(2.96 \mathrm{~m})$. Fitting functions are shown for both orthogonal (black solid line) and standard (violet solid line) linear regressions. The scatterplot includes quantile density contours based on a bivariate kernel density estimation.

the MBR (using temperature as proxy scalar) were comparatively more sensitive to varying micrometeorological conditions than the other gradient-based method (median 23.6\% versus $15.0 \%$ during IC no. 1 and IC no. 2).

\section{Discussion}

The estimated uncertainty in $\Delta C_{\text {REA }}$ is comparatively greater than the $\Delta C$ in gradient and chamber methods (Table 1). This is a major source that contributes to the greater overall uncertainty in REA-measured flux. One of the difficulties in accurately quantifying $\Delta C_{\mathrm{REA}}$ is that the $\mathrm{Hg}^{0}$ concentration detected by the REA apparatus may not truly represent the actual ambient concentration. However, this issue has not been investigated in earlier $\mathrm{Hg}^{0}$ flux measurement using REA. During our campaign, we carefully investigated the REA sampling conformity to this criterion. Although the scatterplot of $C^{\mathrm{REA}}$ and $C_{Z_{2}}$ exhibits a relatively good linear trend, the deviation from the $1: 1$ line is significant ( $p<0.01$, Fig. 12).

The REA system utilizes zero-air injection and is equipped with actuators to suppress pressure differentials occurring in the upstream zone of the fast-response sampling valves that promotes constant flow rate characteristics (Sommar et al., 2013b). This scheme (the effective sampling time per conditional channel is on average $\sim 39 \%$ ) yielded substantially lower $(\sim 70 \%) \mathrm{Hg}$ mass loadings per sample cycle $(5 \mathrm{~min})$ compared to concentration profile measurements. Furthermore, the conditional sampling volumes on an undiluted basis are not static over time, since moderate imbalances in updraft and downdraft events normally occur during regular REA operation. In addition, the temporal variability of 
$\mathrm{Hg}^{0}$ in ambient air is pronounced at the site. As mentioned in Sect. 3.1, the 2537B instrument coupled with REA was operated under a revised set of peak integration parameters to alleviate for low sample loadings to be addressed (Swartzendruber et al., 2009). From the estimation of bivariate kernel densities given in Fig. 12, there appears to be a tendency towards a biased low response from the REA-CVAFS system in the lowest concentration range $\left(C_{Z_{2}} \leq 3 \mathrm{ng} \mathrm{m}^{-3}\right)$. The cluster of higher kernel densities here represents samples with systematic volume differences between the two conditional reservoirs. Therefore, we suggest that REA system using $\mathrm{Hg}$-free air injection application should be operated with sampling cycles of increased duration (sampling volumes). Modifications facilitating QA / QC measures of the REA system (Arnts et al., 2013) are also prompted to pinpoint the cause of this discrepancy. To address the performance of their $\mathrm{Hg}^{0}$ REA system, Cobos et al. (2002) used both open- and integrated closed-path infrared gas analyzers to directly measure turbulent fluxes of water vapor by EC and REA, respectively, and thereby obtain a cross-comparison.

A disadvantage in coupling the flux measurement techniques with a single-channel gas analyzer (e.g., Tekran 2537) is the temporally asynchronous samples obtained for the calculation of $\Delta C$. Under the shifting $\mathrm{Hg}^{0}$ concentrations encountered, the asynchronous sampling uncertainties were found in general to be substantial for all MM techniques (Table 1). In some other studies (Edwards et al., 2005; Lee et al., 2000), simulations of the effect of sequential sampling indicated for AGM-derived $\mathrm{Hg}^{0}$ fluxes a minor or non-significant contribution. For the application of the MBR technique in forest ecosystems, Meyers et al. (1996) reported $\sim 15 \%$ relative uncertainty in the calculation of $\Delta C_{\text {grad. }}$ due to intermittent sampling. For flux measurements, it is desirable to derive $\Delta C$ from synchronous samples, and therefore a dualchannel $\mathrm{Hg}^{0}$ analyzer with alternating pre-concentration of the analyte on a pair of gold traps for each channel (if such an instrument was commercially available) would be ideal.

There are additional sources contributing to the uncertainty and bias in $\mathrm{Hg}^{0}$ flux measurements. For example, the estimation of DFC flux bias was based on an empirical model, and therefore the results are subject to the limitation of the regression models. Application of MM techniques relies on the assumption of a non-divergent vertical flux (Loubet et al., 2009). However, the vertical flux measured at a height may differ from the actual flux at the surface, as a consequence of either horizontal gradients (advection) or changes in storage (changes in concentration with time). Steen et al. (2009) and Fritsche et al. (2008) noted that inconsistent $\mathrm{Hg}^{0}$ concentration gradients can occasionally occur and impair the surface flux derivation. Analogously, performing multiple-level $\mathrm{Hg}^{0}$ concentration profiling, Edwards et al. (2005) reported large flux divergence as intermittently occurring for one (cinnabar-enriched fault zone) out of several sites representing contrasting geological settings of Canada. However, in the case of homogeneous substrate set- tings (comparable $\mathrm{Hg}$ content with this study), these authors stated the effect of local advection yielding flux divergence to be small. In Part I, we assessed that changes in storage had a minor effect on the turbulent fluxes, as could be expected given the relatively low measurement height and the relative magnitude of surface $\mathrm{Hg}^{0}$ efflux during this inter-comparison (Zhu et al., 2015).

\section{Conclusions and recommendations}

In this paper, five contemporary $\mathrm{Hg}^{0}$ flux measurement systems, including two types of DFCs (novel and traditional designs) and three types of MM systems (REA, AGM, and MBR), have been characterized through a detailed measurement error analysis. It was found that the precision in concentration difference measurement poses a critical constraint on obtaining a larger fraction of significant $\mathrm{Hg}^{0}$ fluxes using MM methods. In-field determined precision of $\delta_{\Delta C} / \Delta C$ for MM-CVAFS systems was in the ranges of 1.8-2.1\% (gradient) and 4.2-4.4\% (REA) based on ambient air median $\mathrm{Hg}^{0}$ concentrations during the campaigns. Accordingly, $\sim 38-43 \%$ of the gradient flux data and $45 \%$ of the REA flux data were not significantly different from 0 . Since the concentration differences were acquired from asynchronous samples, we estimated the corresponding uncertainty caused by the asynchronous measurement in the MM techniques to be $33-62 \%$ of total uncertainty. Short-term variability in $\mathrm{Hg}^{0}$ concentration contributes significantly to the uncertainty level in DFC-derived flux, which rendered a majority of non-significant night-time fluxes. The highest DFCs flux bias runs up to $\sim 10 \%$ of the $\mathrm{Hg}^{0}$ flux but, for $\sim 85 \%$ of the observations, the absolute uncertainty ranged from -2 to $2 \mathrm{ng} \mathrm{m}^{-2} \mathrm{~h}^{-1}$. The flux biases of the NDFC and TDFC methods show a distinct diurnal cycle.

The highest relative median flux uncertainty was observed for the REA technique ( $24 \%$, IC no. 2), followed by 24 and $15 \%$ for MBR, and 15 and $12 \%$ for AGM during IC no. 1 and no. 2, respectively. Overall, a higher imprecision in $\mathrm{Hg}^{0}$ concentration measurement during REA application indicates technical limitations in accurately isolating conditional samples in our system. The precision requirements for the involved measurement systems to resolve flux with regard to atmospheric stability and measurement heights obtained in this study provide a guideline for future application. It is indicated that flux-gradient-based techniques (MBR and AGM) may well be deployed in favor of a REA system to quantify $\mathrm{Hg}^{0}$ air-ecosystem exchange over low vegetation. The inability to obtain temporally synchronous samples for the calculation of $\mathrm{Hg}^{0}$ concentration difference in flux measurement impairs the accuracy of MM-derived fluxes under short-term varying concentrations of ambient $\mathrm{Hg}^{0}$. For future applications, especially under non-background field conditions, it is therefore recommended to accomplish $\Delta C$ derivation from simultaneous collected samples. 
Appendix A: Nomenclature

\begin{tabular}{|c|c|c|}
\hline Symbols & Explanation & Unit \\
\hline$A$ & Dynamic flux chamber footprint & $\mathrm{m}^{2}$ \\
\hline $\mathrm{AP}_{x}$ & Atmospheric parameter for flux measurement method $x(*)$ & $\mathrm{h} \mathrm{m}^{-1}$ \\
\hline$C_{z}$ & Ambient $\mathrm{Hg}^{0}$ concentration at measurement height $z$ (gradient-based methods) & $\mathrm{ng} \mathrm{m}^{-3}$ \\
\hline$C_{\text {out }}$ & $\mathrm{Hg}^{0}$ concentration in DFC outlet air & $\mathrm{ng} \mathrm{m}^{-3}$ \\
\hline$C_{\text {in }}$ & $\mathrm{Hg}^{0}$ concentration in DFC inlet air & $\mathrm{ng} \mathrm{m}^{-3}$ \\
\hline$c_{p}$ & Specific heat of air at constant pressure & $\mathrm{J} \mathrm{kg}^{-1} \mathrm{~K}^{-1}$ \\
\hline$\Delta C$ & $\mathrm{Hg}^{0}$ concentration difference (non-specific) & $\mathrm{ng} \mathrm{m}^{-3}$ \\
\hline$\Delta \mathbb{C}$ & Method-specific analyzer concentration difference resolution & $\mathrm{ng} \mathrm{m}^{-3}$ \\
\hline$\Delta C_{\text {grad. }}$ & Vertical $\mathrm{Hg}^{0}$ concentration gradient & $\mathrm{ng} \mathrm{m}^{-3}$ \\
\hline$\Delta C_{\mathrm{REA}}$ & $\begin{array}{l}\text { Time-averaged } \mathrm{Hg}^{0} \text { concentration difference between conditional samples }\left(\Delta C_{\mathrm{REA}}=\right. \\
\left.\overline{C^{\uparrow}}-\overline{C^{\downarrow}}\right)\end{array}$ & $\mathrm{ng} \mathrm{m}^{-3}$ \\
\hline$\Delta C_{\text {enclosure }}$ & Difference in $\mathrm{Hg}^{0}$ concentration between DFC outlet and inlet air & $n g m^{-3}$ \\
\hline$\Delta C_{\text {blank }}$ & $\begin{array}{l}\text { Difference in } \mathrm{Hg}^{0} \text { concentration between DFC outlet and inlet air when measuring DFC } \\
\text { blank from an inert surface }\end{array}$ & $\mathrm{ng} \mathrm{m}^{-3}$ \\
\hline$C^{\uparrow / \downarrow}$ & $\begin{array}{l}\text { Conditionally sampled } \mathrm{Hg}^{0} \text { concentration for updraft/downdraft air parcels (corrected for } \\
\text { dilution by zero-air injection) measured at height } z\end{array}$ & $n g m^{-3}$ \\
\hline$C^{\mathrm{REA}}$ & Average $\mathrm{Hg}^{0}$ concentration in accumulated updrafts and downdrafts measured at height $z$ & $n g m^{-3}$ \\
\hline$d$ & Zero plane displacement height & \\
\hline$D_{\mathrm{Hg}^{0}}$,air & $\mathrm{Hg}^{0}$ diffusivity in air & $\mathrm{m}^{2} \mathrm{~s}^{-1}$ \\
\hline & Similarity function for the standard deviation of vertical wind velocity & - \\
\hline$F^{\mathrm{TDFC}}$ & $\mathrm{Hg}^{0}$ flux gauged by the traditional DFC (TDFC) method & $n g m^{-2} h^{-1}$ \\
\hline$F^{\mathrm{NDFC}}$ & $\mathrm{Hg}^{0}$ flux gauged by the novel DFC (NDFC) method & $n g m^{-2} h^{-1}$ \\
\hline$\left.F^{\mathrm{REA}}\right|_{z}$ & Turbulent $\mathrm{Hg}^{0}$ flux gauged by the REA method (at measurement height $z$ ) & $n g m^{-2} h^{-1}$ \\
\hline$F^{\mathrm{MBR}}$ & Turbulent $\mathrm{Hg}^{0}$ flux gauged by the MBR method & $n g \mathrm{~m}^{-2} \mathrm{~h}^{-1}$ \\
\hline$F^{\mathrm{AGM}}$ & Turbulent $\mathrm{Hg}^{0}$ flux gauged by AGM measurements & $n g \mathrm{~m}^{-2} \mathrm{~h}^{-1}$ \\
\hline$\hat{F}_{\mathrm{DFC}}$ & $\begin{array}{l}\text { Predicted } \mathrm{Hg}^{0} \text { DFC flux from empirical model using chamber internal environmental } \\
\text { variables as input }\end{array}$ & $\operatorname{ng~m}^{-2} \mathrm{~h}^{-1}$ \\
\hline$\hat{F}_{N}$ & $\begin{array}{l}\text { Predicted } \mathrm{Hg}^{0} \text { DFC flux from empirical model using ambient environmental variables as } \\
\text { input }\end{array}$ & $\operatorname{ng~m}{ }^{-2} h^{-1}$ \\
\hline$|F|$ & The modulus of flux & $n g \mathrm{~m}^{-2} \mathrm{~h}^{-1}$ \\
\hline$H$ & Sensible heat flux $\left(\rho \cdot c_{p} \cdot \overline{w^{\prime} T^{\prime}}\right)$ & $\mathrm{W} \mathrm{m}^{-2}$ \\
\hline$H_{\mathrm{S}}$ & Buoyancy heat flux $\left(\rho \cdot c_{p} \cdot \overline{w^{\prime} T_{\mathrm{s}}^{\prime}}\right)$ & $\mathrm{W} \mathrm{m}^{-2}$ \\
\hline$k_{\text {mass(a) }}$ & Overall mass transfer coefficient under atmospheric condition & $\mathrm{m} \mathrm{s}^{-1}$ \\
\hline$k_{\text {mass(m) }}$ & Overall mass transfer coefficient in the NDFC & $\mathrm{m} \mathrm{s}^{-1}$ \\
\hline$K_{H}$ & Turbulent diffusion coefficient of sensible heat & $\mathrm{m}^{2} \mathrm{~s}^{-1}$ \\
\hline$L$ & Monin-Obukhov length & $\mathrm{m}$ \\
\hline$m_{i}^{\uparrow / \downarrow}$ & Mass of $\mathrm{Hg}^{0}$ collected in accumulated updraft/downdraft sample $i$ & \\
\hline$Q$ & DFC flushing flow rate & $\mathrm{m}^{3} \mathrm{~h}^{-1}$ \\
\hline$Q_{i}^{\uparrow / \downarrow}$ & Flow rate through the updraft/downdraft channels for sample $i$ & $\mathrm{Lmin}^{-1}$ \\
\hline $\mathbb{R}^{l}$ & Uncertainty level in the flux measurement & - \\
\hline Re & Reynolds number & - \\
\hline$S$ & Irradiance & $\mathrm{W} \mathrm{m}^{-2}$ \\
\hline$t_{i}$ & Time duration of updraft/downdraft sample $i$ & $\min$ \\
\hline$T_{z}$ & Air temperature at height $z$ & $\mathrm{~K}$ \\
\hline$T_{\mathrm{S}}$ & Sonic air temperature & K \\
\hline$T_{\mathrm{s}}^{\uparrow / \downarrow}$ & Conditionally sampled $T_{\mathrm{S}}$ for updraft/downdraft air parcels & K \\
\hline$\Delta T_{\mathrm{s}, \mathrm{REA}}$ & Time-averaged $T_{\mathrm{S}}$ difference between conditional samples $\left(\Delta T_{\mathrm{S}, \mathrm{REA}}=\overline{T_{\mathrm{S}}^{\uparrow}}-\overline{T_{\mathrm{S}}^{\downarrow}}\right)$ & $\mathrm{K}$ \\
\hline$T_{\text {soil }}$ & Surface soil temperature & ${ }^{\circ} \mathrm{C}$ \\
\hline$\Delta T_{\text {grad. }}$ & Vertical air temperature gradient & $\mathrm{K}$ \\
\hline$u_{*}$ & Friction velocity & $\mathrm{m} \mathrm{s}^{-1}$ \\
\hline$w$ & Vertical component of the wind velocity & $\mathrm{ms}^{-1}$ \\
\hline$w_{\text {DB }}$ & Vertical wind deadband threshold for conditional sampling & $\mathrm{m} \mathrm{s}^{-1}$ \\
\hline$\frac{D D}{w^{\prime} T^{\prime}}$ & Kinematic heat flux & $\mathrm{Km} \mathrm{s}^{-1}$ \\
\hline$\overline{w_{x^{\prime}}}$ & $w$ averaged over time interval $x^{\prime}\left(x^{\prime}=5\right.$ or $\left.20 \mathrm{~min}\right)$ & $\mathrm{m} \mathrm{s}^{-1}$ \\
\hline$z$ & Sampling height (above ground level) & $\mathrm{m}$ \\
\hline$z_{0}$ & Surface roughness height & $\mathrm{m}$ \\
\hline$\alpha_{i}^{\uparrow / \downarrow}$ & $\begin{array}{l}\text { Fraction of total time the updraft or downdraft isolation valves were activated for during } \\
\text { sample } i\end{array}$ & $\%$ \\
\hline$\beta_{S}$ & $\begin{array}{l}\text { Relaxation coefficient used in the REA method (derived for generic scalar } s \text {; in this work, } \\
\beta_{T_{\mathrm{s}}} \text { was used) }\end{array}$ & - \\
\hline
\end{tabular}




\begin{tabular}{|c|c|c|}
\hline Symbols & Explanation & Unit \\
\hline$\gamma$ & Dimensionless constant & - \\
\hline$\delta_{x}$ & Uncertainty for specific parameter or flux measurement method " $x$ " & Follows the units of " $x$ " \\
\hline$\delta_{\Delta C_{\mathrm{MM}}}$ & $\begin{array}{l}\text { Uncertainty in concentration difference measurement for MM } \\
\text { gradient) flux methods: } \delta_{\Delta C_{\mathrm{MM}}}= \pm \sqrt{\left(\delta_{\Delta C_{\mathrm{MM}} \text { channel }}^{\text {che }}\right)^{2}+\left(\delta_{\Delta C_{\mathrm{MM}}}^{\mathrm{IS}}\right)^{2}}\end{array}$ & $\mathrm{ng} \mathrm{m}^{-3}$ \\
\hline$\delta_{\Delta C_{\mathrm{MM}}}^{\text {channel }}$ & $\begin{array}{l}\text { Uncertainty in concentration difference measurement due to gas sampling } \\
\text { channels for MM (REA or gradient) flux methods }\end{array}$ & $\mathrm{ng} \mathrm{m}^{-3}$ \\
\hline$\delta_{\Delta C_{\mathrm{MM}}}^{\mathrm{IS}}$ & $\begin{array}{l}\text { Uncertainty in concentration difference measurement due to intermittent } \\
\text { sampling for MM (REA or gradient) flux methods }\end{array}$ & $\mathrm{ng} \mathrm{m}^{-3}$ \\
\hline$\delta_{\Delta C_{\text {enclosure }}}$ & $\begin{array}{l}\text { Combined uncertainty in } \Delta C_{\text {enclosure due to intermittent sampling of DFC }} \\
\text { inlet and outlet air as well as DFC blank determination: } \delta_{\Delta C_{\text {enclosure }}}= \\
\pm \sqrt{\left(\delta_{\Delta C_{\text {enclosure }}}^{\text {IS }}\right)^{2}+\delta_{\Delta C_{\text {blank }}}^{2}} .\end{array}$ & $\mathrm{ng} \mathrm{m}^{-3}$ \\
\hline$\delta_{\Delta C_{\text {enclosure }}}^{\mathrm{IS}}$ & $\begin{array}{l}\text { Uncertainty in } \Delta C_{\text {enclosure due to intermittent sampling of DFC inlet and }} \\
\text { outlet air }\end{array}$ & $\mathrm{ng} \mathrm{m}^{-3}$ \\
\hline$\delta_{\Delta C_{\text {blank }}}$ & Uncertainty in the DFC blank measurement & $\mathrm{ng} \mathrm{m}^{-3}$ \\
\hline$\varepsilon_{x}$ & Bias for specific parameter or flux measurement method " $x$ " & Follows the units of " $x$ " \\
\hline 5 & Atmospheric stability parameter: $\varsigma=(z-d) / L$ & - \\
\hline$\kappa$ & von Kármán constant & - \\
\hline$v_{\text {tr }}$ & Transfer velocity (used in the AGM technique) & $\mathrm{ms}^{-1}$ \\
\hline$\sigma_{w}$ & Standard deviation of $w$ & $\mathrm{~ms}^{-1}$ \\
\hline$\overline{\sigma_{w, x^{\prime}}}$ & $\sigma_{w}$ averaged over time interval $x^{\prime}\left(x^{\prime}=5\right.$ or $\left.20 \mathrm{~min}\right)$ & $\mathrm{ms}^{-1}$ \\
\hline$\rho$ & Air density & $\mathrm{kg} \mathrm{m}^{-3}$ \\
\hline$\tau$ & Momentum flux & $\mathrm{kg} \mathrm{m}^{-1} \mathrm{~s}^{-2}$ \\
\hline$\psi_{H}$ & Integrated universal function for heat & - \\
\hline
\end{tabular}

Notes: $\left(^{*}\right)$ the "atmosphere parameter" can be specified as $4 /\left[5 \cdot \beta_{s} \cdot f_{w}\left(\varsigma_{2}\right)\right]$ and $\left[\ln \left(\frac{z_{2}-d}{z_{1}-d}\right)-\psi_{H}\left(\varsigma_{2}\right)+\psi_{H}\left(\varsigma_{1}\right)\right] / \kappa$ for REA and gradient methods, respectively, where the similarity functions of $\sigma_{w}\left(f_{w}(\varsigma)\right.$ and $\left.\psi_{H}(\varsigma)\right)$ were adopted from Rowe et al. (2011) and Businger et al. (1971), respectively. 
Acknowledgements. This research was financially supported by the 973 Program (2013CB430002), the National Science Foundation of China (41030752), the Chinese Academy of Sciences through an instrument development program (YZ200910), and the State Key Laboratory of Environmental Geochemistry. We would like to express our gratitude to the staff from Yucheng Comprehensive Experimental Station, Chinese Academy of Sciences, for sampling and logistical assistance.

Edited by: L. Zhang

\section{References}

Ammann, C.: On the Applicability of Relaxed Eddy Accumulation and Common Methods for Measuring Trace Gas Surface Fluxes, Ph. D. thesis, ETH, Zürich, 239 pp., 1998.

Ammann, C. and Meixner, F. X.: Stability dependence of the relaxed eddy accumulation coefficient for various scalar quantities, J. Geophys. Res.-Atmos., 107, 4071, doi:10.1029/2001JD000649, 2002.

Aubinet, M., Vesala, T., and Papale, D.: Eddy covariance: a Practical Guide to Measurement and Data Analysis, Springer, Dordrecht, the Netherlands, 2012.

Arnts, R. R., Mowry, F. L., and Hampton, G. A.: A highfrequency response relaxed eddy accumulation flux measurement system for sampling short-lived biogenic volatile organic compounds, J. Geophys. Res.-Atmos., 118, 4860-4873, doi:10.1002/jgrd.50215, 2013.

Baker, J. M., Norman, J. M., and Bland, W. L.: Field-Scale Application of Flux Measurement by Conditional Sampling, Agr. Forest Meteorol., 62, 31-52, doi:10.1016/0168-1923(92)90004N, 1992.

Bash, J. O. and Miller, D. R.: A relaxed eddy accumulation system for measuring surface fluxes of total gaseous mercury, J. Atmos. Ocean. Technol., 25, 244-257, doi:10.1175/2007JTECHA908.1, 2008.

Bash, J. O. and Miller, D. R.: Growing season total gaseous mercury (TGM) flux measurements over an Acer rubrum L. stand, Atmos. Environ., 43, 5953-5961, doi:10.1016/j.atmosenv.2009.08.008, 2009.

Bauer, D., Everhart, S., Remeika, J., Tatum Ernest, C., and Hynes, A. J.: Deployment of a sequential two-photon laser-induced fluorescence sensor for the detection of gaseous elemental mercury at ambient levels: fast, specific, ultrasensitive detection with partsper-quadrillion sensitivity, Atmos. Meas. Tech., 7, 4251-4265, doi:10.5194/amt-7-4251-2014, 2014.

Billesbach, D.: Estimating uncertainties in individual eddy covariance flux measurements: A comparison of methods and a proposed new method, Agr. Forest Meteorol., 151, 394-405, doi:10.1016/j.agrformet.2010.12.001, 2011.

Bowling, D. R., Turnipseed, A. A., Delany, A. C., Baldocchi, D. D., Greenberg, J. P., and Monson, R. K.: The use of relaxed eddy accumulation to measure biosphere-atmosphere exchange of isoprene and other biological trace gases, Oecologia, 116, 306-315, doi:10.1007/s004420050592, 1998.

Brown, R. J. and Brown, A. S.: Accurate calibration of mercury vapour measurements, Analyst, 133, 1611-1618, doi:10.1039/B806860G, 2008.
Businger, J.: Evaluation of the accuracy with which dry deposition can be measured with current micrometeorological techniques, J. Clim. Appl. Meteorol., 25, 1100-1124, doi:10.1175/15200450(1986)025<1100:EOTAWW>2.0.CO;2, 1986.

Businger, J. A. and Delany, A. C.: Chemical sensor resolution required for measuring surface fluxes by three common micrometeorological techniques, J. Atmos. Chem., 10, 399-410, doi:10.1007/BF00115782, 1990.

Businger, J. A., Wyngaard, J. C., Izumi, Y., and Bradley, E. F.: Flux-profile relationships in the atmospheric surface layer, J. Atmos. Sci., 28, 181-189, doi:10.1175/15200469(1971)028<0181:FPRITA>2.0.CO;2, 1971.

Cantrell, C. A.: Technical Note: Review of methods for linear leastsquares fitting of data and application to atmospheric chemistry problems, Atmos. Chem. Phys., 8, 5477-5487, doi:10.5194/acp8-5477-2008, 2008.

Carpi, A., Frei, A., Cocris, D., McCloskey, R., Contreras, E., and Ferguson, K.: Analytical artifacts produced by a polycarbonate chamber compared to a Teflon chamber for measuring surface mercury fluxes, Anal. Bioanal. Chem., 388, 361-365, doi:10.1007/s00216-006-1111-0, 2007.

Cobos, D. R., Baker, J. M., and Nater, E. A.: Conditional sampling for measuring mercury vapor fluxes, Atmos. Environ., 36, 43094321, doi:10.1016/S1352-2310(02)00400-4, 2002.

Converse, A. D., Riscassi, A. L., and Scanlon, T. M.: Seasonal variability in gaseous mercury fluxes measured in a high-elevation meadow, Atmos. Environ., 44, 2176-2185, doi:10.1016/j.atmosenv.2010.03.024, 2010.

Denmead, O. T.: Approaches to measuring fluxes of methane and nitrous oxide between landscapes and the atmosphere, Plant Soil, 309, 5-24, doi:10.1007/s11104-008-9599-z, 2008.

Dumarey, R., Temmerman, E., Adams, R., and Hoste, J.: The accuracy of the vapour-injection calibration method for the determination of mercury by amalgamation/cold-vapour atomic absorption spectrometry, Anal. Chim. Acta, 170, 337-340, doi:10.1016/S0003-2670(00)81759-6, 1985.

Dumarey, R., Brown, R. J., Corns, W. T., Brown, A. S., and Stockwell, P. B.: Elemental mercury vapour in air: the origins and validation of the "Dumarey equation" describing the mass concentration at saturation, Accredit. Qual. Assur., 15, 409-414, doi:10.1007/s00769-010-0645-1, 2010.

Eckley, C. S., Gustin, M., Lin, C. J., Li, X., and Miller, M. B.: The influence of dynamic chamber design and operating parameters on calculated surface-to-air mercury fluxes, Atmos. Environ., 44, 194-203, doi:10.1016/j.atmosenv.2009.10.013, 2010.

Edwards, G. C., Rasmussen, P. E., Schroeder, W. H., Wallace, D. M., Halfpenny-Mitchell, L., Dias, G. M., Kemp, R. J., and Ausma, S.: Development and evaluation of a sampling system to determine gaseous Mercury fluxes using an aerodynamic micrometeorological gradient method, J. Geophys. Res.-Atmos., 110, D10306, doi:10.1029/2004jd005187, 2005.

Ellison, S. L. R. and Williams, A.: Quantifying uncertainty in analytical measurement, EURACHEM/CITAC Guide 4, 3rd Edn., 133 pp., available at: http://www.citac.cc/QUAM2012_P1.pdf (last access: 10 May 2015), 2012.

Finkelstein, P. L. and Sims, P. F.: Sampling error in eddy correlation flux measurements, J. Geophys. Res.-Atmos., 106, 3503-3509, doi:10.1029/2000JD900731, 2001. 
Foken, T.: Micrometeorology, Springer-Verlag, Berlin, Heidelberg, 306 pp., 2008.

Fratini, G. and Mauder, M.: Towards a consistent eddy-covariance processing: an intercomparison of EddyPro and TK3, Atmos. Meas. Tech., 7, 2273-2281, doi:10.5194/amt-7-2273-2014, 2014.

Fritsche, J., Obrist, D., Zeeman, M. J., Conen, F., Eugster, W., and Alewell, C.: Elemental mercury fluxes over a sub-alpine grassland determined with two micrometeorological methods, Atmos. Environ., 42, 2922-2933, doi:10.1016/j.atmosenv.2007.12.055, 2008.

Garratt, J. R. and Taylor, P. A.: Boundary-Layer Meteorology 25th Anniversary Volume, 1970-1995: Invited Reviews and Selected Contributions to Recognise Ted Munn's Contribution as Editor over the Past 25 Years, Springer Netherlands, 417 pp., doi:10.1007/978-94-017-0944-6, 1996.

Goodrow, S. M., Miskewitz, R., Hires, R. I., Eisenreich, S. J., Douglas, W. S., and Reinfelder, J. R.: Mercury emissions from cement-stabilized dredged material, Environ. Sci. Technol., 39, 8185-8190, doi:10.1021/es050506n, 2005.

Gustin, M. S.: Exchange of mercury between the atmosphere and terrestrial ecosystems, in: Environmental Chemistry and Toxicology of Mercury, edited by: Liu, G. L., Cai, Y., and O'Driscoll, N., John Wiley \& Sons, Inc., Hoboken, NJ, USA, 423-451, doi:10.1002/9781118146644, 2011.

Gustin, M. S. and Lindberg, S. E.: Assessing the contribution of natural sources to the global mercury cycle: The importance of intercomparing dynamic flux measurements, Fresen, J. Anal. Chem., 366, 417-422, doi:10.1007/s002160050085, 2000.

Hensen, A., Nemitz, E., Flynn, M., Blatter, A., Jones, S., Sørensen, L. L., Hensen, B., Pryor, S., Jensen, B., and Otjes, R.: Intercomparison of ammonia fluxes obtained using the Relaxed Eddy Accumulation technique, Biogeosciences, 6, 2575-2588, doi:10.5194/bg-6-2575-2009, 2009.

Kramm, G., Beier, N., Dlugi, R., and Müller, H.: Evaluation of conditional sampling methods, Contrib. Atmos. Phys., 72, 161-172, 1999.

Lee, X., Benoit, G., and Hu, X. Z.: Total gaseous mercury concentration and flux over a coastal saltmarsh vegetation in Connecticut, USA, Atmos. Environ., 34, 4205-4213, doi:10.1016/S13522310(99)00487-2, 2000.

Lin, C.-J., Gustin, M. S., Singhasuk, P., Eckley, C., and Miller, M.: Empirical models for estimating mercury flux from soils, Environ. Sci. Technol., 44, 8522-8528, doi:10.1021/es1021735, 2010.

Lin, C.-J., Zhu, W., Li, X., Feng, X., Sommar, J., and Shang, L.: Novel dynamic flux chamber for measuring air-surface exchange of $\mathrm{Hg}^{0}$ from soils, Environ. Sci. Technol., 46, 89108920, doi:10.1021/es3012386, 2012.

Lindberg, S. E., Zhang, H., Vette, A. F., Gustin, M. S., Barnett, M. O., and Kuiken, T.: Dynamic flux chamber measurement of gaseous mercury emission fluxes over soils: Part 2 - effect of flushing flow rate and verification of a two-resistance exchange interface simulation model, Atmos. Environ., 36, 847859, doi:10.1016/S1352-2310(01)00502-7, 2002.

Loubet, B., Milford, C., Hensen, A., Daemmgen, U., Erisman, J. W., Cellier, P., and Sutton, M. A.: Advection of $\mathrm{NH}_{3}$ over a pasture field and its effect on gradient flux measurements, Biogeosciences, 6, 1295-1309, doi:10.5194/bg-6-1295-2009, 2009.
Marsik, F. J., Keeler, G. J., Lindberg, S. E., and Zhang, H.: Airsurface exchange of gaseous mercury over a mixed sawgrasscattail stand within the Florida Everglades, Environ. Sci. Technol., 39, 4739-4746, doi:10.1021/es0404015, 2005.

Mason, R.: Mercury emissions from natural processes and their importance in the global mercury cycle, in: Mercury Fate and Transport in the Global Atmosphere, edited by: Mason, R. and Pirrone, N., Springer US, 173-191, doi:10.1007/978-0-387-93958-2_7, 2009.

Mauder, M. and Foken, T.: Documentation and instruction manual of the eddy covariance software package TK2, Vol 26, Arbeitsergebnisse, Universitat Bayreuth, Abteilung Mikrometeorologie, Universitat Bayreuth, Abteilung Mikrometeorologie, Bayreuth, 42 pp., ISSN 1614-8916, 2004.

Mauder, M., Cuntz, M., Drüe, C., Graf, A., Rebmann, C., Schmid, H. P., Schmidt, M., and Steinbrecher, R.: A strategy for quality and uncertainty assessment of long-term eddycovariance measurements, Agr. Forest Meteorol., 169, 122-135, doi:10.1016/j.agrformet.2012.09.006, 2013.

Meyers, T. P., Hall, M. E., Lindberg, S. E., and Kim, K.: Use of the modified bowen-ratio technique to measure fluxes of trace gases, Atmos. Environ., 30, 3321-3329, doi:10.1016/13522310(96)00082-9, 1996.

Moravek, A., Trebs, I., and Foken, T.: Effect of imprecise lag time and high-frequency attenuation on surface-atmosphere exchange fluxes determined with the relaxed eddy accumulation method, J. Geophys. Res.-Atmos., 118, 10210-10224, doi:10.1002/jgrd.50763, 2013.

Moravek, A., Foken, T., and Trebs, I.: Application of a GCECD for measurements of biosphere-atmosphere exchange fluxes of peroxyacetyl nitrate using the relaxed eddy accumulation and gradient method, Atmos. Meas. Tech., 7, 2097-2119, doi:10.5194/amt-7-2097-2014, 2014.

National Atmospheric Deposition Program (NADP): Atmospheric Mercury Network Operations Manual (2011-05) Version 1.0., available at: http://nadp.isws.illinois.edu/amn/docs/AMNet_ Operations_Manual.pdf (last access: 10 May 2015),NADP Program Office, 2204 Griffith Dr., Champaign, IL 61820, 2011.

Nemitz, E., Flynn, M., Williams, P., Milford, C., Theobald, M., Blatter, A., Gallagher, M., and Sutton, M.: A relaxed eddy accumulation system for the automated measurement of atmospheric ammonia fluxes, Water Air Soil Poll., 1, 189-202, doi:10.1023/A:1013103122226, 2001.

Olofsson, M., Sommar, J., Ljungström, E., and Andersson, M.: Application of relaxed eddy accumulation techniques to qualify $\mathrm{Hg}^{0}$ fluxes over modified soil surfaces, Water Air Soil Poll., 167, 331354, doi:10.1007/s11270-005-0012-8, 2005.

Park, C., Schade, G. W., and Boedeker, I.: Flux measurements of volatile organic compounds by the relaxed eddy accumulation method combined with a GC-FID system in urban Houston,Texas, Atmos. Environ., 44, 2605-2614, doi:10.1016/j.atmosenv.2010.04.016, 2010.

Pattey, E., Desjardins, R., Boudreau, F., and Rochette, P.: Impact of density fluctuations on flux measurements of trace gases: implications for the relaxed eddy accumulation technique, Bound.Lay. Meteorol., 59, 195-203, doi:10.1007/BF00120695, 1992.

Pierce, A., Obrist, D., Moosmüller, H., Faïn, X., and Moore, C.: Cavity ring-down spectroscopy sensor development for high-time-resolution measurements of gaseous elemental mer- 
cury in ambient air, Atmos. Meas. Tech., 6, 1477-1489, doi:10.5194/amt-6-1477-2013, 2013.

Rowe, M. D., Fairall, C. W., and Perlinger, J. A.: Chemical sensor resolution requirements for near-surface measurements of turbulent fluxes, Atmos. Chem. Phys., 11, 5263-5275, doi:10.5194/acp-11-5263-2011, 2011.

Schade, G. W. and Goldstein, A. H.: Fluxes of oxygenated volatile organic compounds from a ponderosa pine plantation, J. Geophys. Res.-Atmos., 106, 3111-3123, doi:10.1029/2000JD900592, 2001.

Schroeder, W. H. and Munthe, J.: Atmospheric mercury - An overview, Atmos. Environ., 32, 809-822, doi:10.1016/S13522310(97)00293-8, 1998.

Selin, N. E.: Global Biogeochemical Cycling of Mercury: A Review, Annu. Rev. Env. Resour., 34, 43-63, doi:10.1146/annurev.environ.051308.084314, 2009.

Smith, L. M. and Reinfelder, J. R.: Mercury volatilization from salt marsh sediments, J. Geophys. Res., 114, G00C09, doi:10.1029/2009jg000979, 2009.

Sommar, J., Zhu, W., Lin, C.-J., and Feng, X.: Field approaches to measure $\mathrm{Hg}$ exchange between natural surfaces and the atmosphere - a review, Crit. Rev. Environ. Sci. Technol., 43, 16571739, doi:10.1080/10643389.2012.671733, 2013a.

Sommar, J., Zhu, W., Shang, L., Feng, X., and Lin, C.-J.: A wholeair relaxed eddy accumulation measurement system for sampling vertical vapour exchange of elemental mercury, Tellus B, 65, 19940, doi:10.3402/tellusb.v65i0.19940, 2013b.

Steen, A. O., Berg, T., Dastoor, A. P., Durnford, D. A., Hole, L. R., and Pfaffhuber, K. A.: Dynamic exchange of gaseous elemental mercury during polar night and day, Atmos. Environ., 43, 56045610, doi:10.1016/j.atmosenv.2009.07.069, 2009.

Swartzendruber, P. C., Jaffe, D. A., and Finley, B.: Improved fluorescence peak integration in the Tekran 2537 for applications with sub-optimal sample loadings, Atmos. Environ., 43, 36483651, doi:10.1016/j.atmosenv.2009.02.063, 2009.

Walker, J., Robarge, W., Wu, Y., and Meyers, T.: Measurement of bi-directional ammonia fluxes over soybean using the modified Bowen-ratio technique, Agr. Forest Meteorol., 138, 54-68, doi:10.1016/j.agrformet.2006.03.011, 2006.
Walker, J. T., Jones, M. R., Bash, J. O., Myles, L., Meyers, T., Schwede, D., Herrick, J., Nemitz, E., and Robarge, W.: Processes of ammonia air-surface exchange in a fertilized Zea mays canopy, Biogeosciences, 10, 981-988, doi:10.5194/bg-10-9812013, 2013.

Wallschläger, D., Turner, R. R., London, J., Ebinghaus, R., Kock, H. H., Sommar, J., and Xiao, Z. F.: Factors affecting the measurement of mercury emissions from soils with flux chambers, J. Geophys. Res.-Atmos., 104, 21859-21871, doi:10.1029/1999JD900314, 1999.

Wolff, V., Trebs, I., Ammann, C., and Meixner, F. X.: Aerodynamic gradient measurements of the $\mathrm{NH}_{3}-\mathrm{HNO}_{3}-\mathrm{NH}_{4} \mathrm{NO}_{3}$ triad using a wet chemical instrument: an analysis of precision requirements and flux errors, Atmos. Meas. Tech., 3, 187-208, doi:10.5194/amt-3-187-2010, 2010.

$\mathrm{Xu}, \mathrm{X}$.: Investigations into the tropospheric cycle of COS: atmospheric distribution, air-sea and air-vegetation exchanges, $\mathrm{PhD}$ thesis, Johann Wolfgang Goethe-Universität, Frankfurt am Main, 177 pp., 2001.

Zhang, H., Lindberg, S. E., Barnett, M. O., Vette, A. F., and Gustin, M. S.: Dynamic flux chamber measurement of gaseous mercury emission fluxes over soils. Part 1: simulation of gaseous mercury emissions from soils using a two-resistance exchange interface model, Atmos. Environ., 36, 835-846, doi:10.1016/S13522310(01)00501-5, 2002.

Zhu, W., Sommar, J., Li, Z., Feng, X., Lin, C.-J., and Li, G.: Highly elevated emission of mercury vapor due to the spontaneous combustion of refuse in a landfill, Atmos. Environ., 79, 540-545, doi:10.1016/j.atmosenv.2013.07.016, 2013a.

Zhu, W., Li, Z., Chai, X., Hao, Y., Lin, C.-J., Sommar, J., and Feng, $\mathrm{X}$. : Emission characteristics and air-surface exchange of gaseous mercury at the largest active landfill in Asia, Atmos. Environ., 79, 188-197, doi:10.1016/j.atmosenv.2013.05.083, 2013b.

Zhu, W., Sommar, J., Lin, C.-J., and Feng, X.: Mercury vapor air-surface exchange measured by collocated micrometeorological and enclosure methods - Part I: Data comparability and method characteristics, Atmos. Chem. Phys., 15, 685-702, doi:10.5194/acp-15-685-2015, 2015. 